\title{
XIV.
}

\section{Studien über die Zellen im Auswurf und in entziindlichen Ausscheidungen des Menschen}

von

Dr. L. Grünwald

in München.

Hierzu Taf. VIII.

Die Zellen des Sputum haben' schon lange vor der Entdeckung jener Färbemittel und Methoden, welche ihre PlasmaStructur aufzudecken gestatteten, das Interesse, vor Allem des Diagnostikers, erweckt. $J_{\theta}$ weniger sichere Anhaltspunkte eine vergangene Zeit für die Unterscheidung verhältnissmässig harmloser Processe der Lunge von destructiven zur Hand hatte, um so mehr suchte sie an neuen und vielfacher Deutung zugängigen Befunden Stützpunkte für oft nur theoretisch construirte pathologische Vorgänge zu gewinnen. So entstand z. B. die pathognomonische Werthung der myelinhaltigen Zellen für die Diagnostik phthisischer Lungenprocesse durch Buhl. Die Möglichkeit, der inneren Beschaffenheit der. Zellen näherzutreten, wie sie uns Flemming's und Ehrlich's Untersuchungs-Methoden geliefert haben, bat nicht nur unsere Kenntnisse in positiver Weise zu erweitern gestattet, sie hat jenem Streben, unbekannte Processe durch neu entdeckte, zwar ihrem Wesen nach unbekannte, aber vielleicht congruente Befunde einer Gleichung entgegen zu führen, wieder neve Nahrung verschafft. So entstand die, man darf wohl schon sagen, Lehre von dem essentiellen, wenn auch immer etwas mystischen Zusammenhang des Asthma mit dem Vorkommen eosinophiler Zellen. Jene Buhl'sche Theorie hatte verhältnissmässig bald ihre Unhaltbarkeit erkennen lassen, als Panizza ${ }^{1}$ besonnen die Sputa von gesunden und kranken, aber nicht phthisischen Personen untersuchte und nachweisen konnte, dass jene gefürchteten Myelinzellen gerade dem Auswurf des gesunden, von der Cultur 


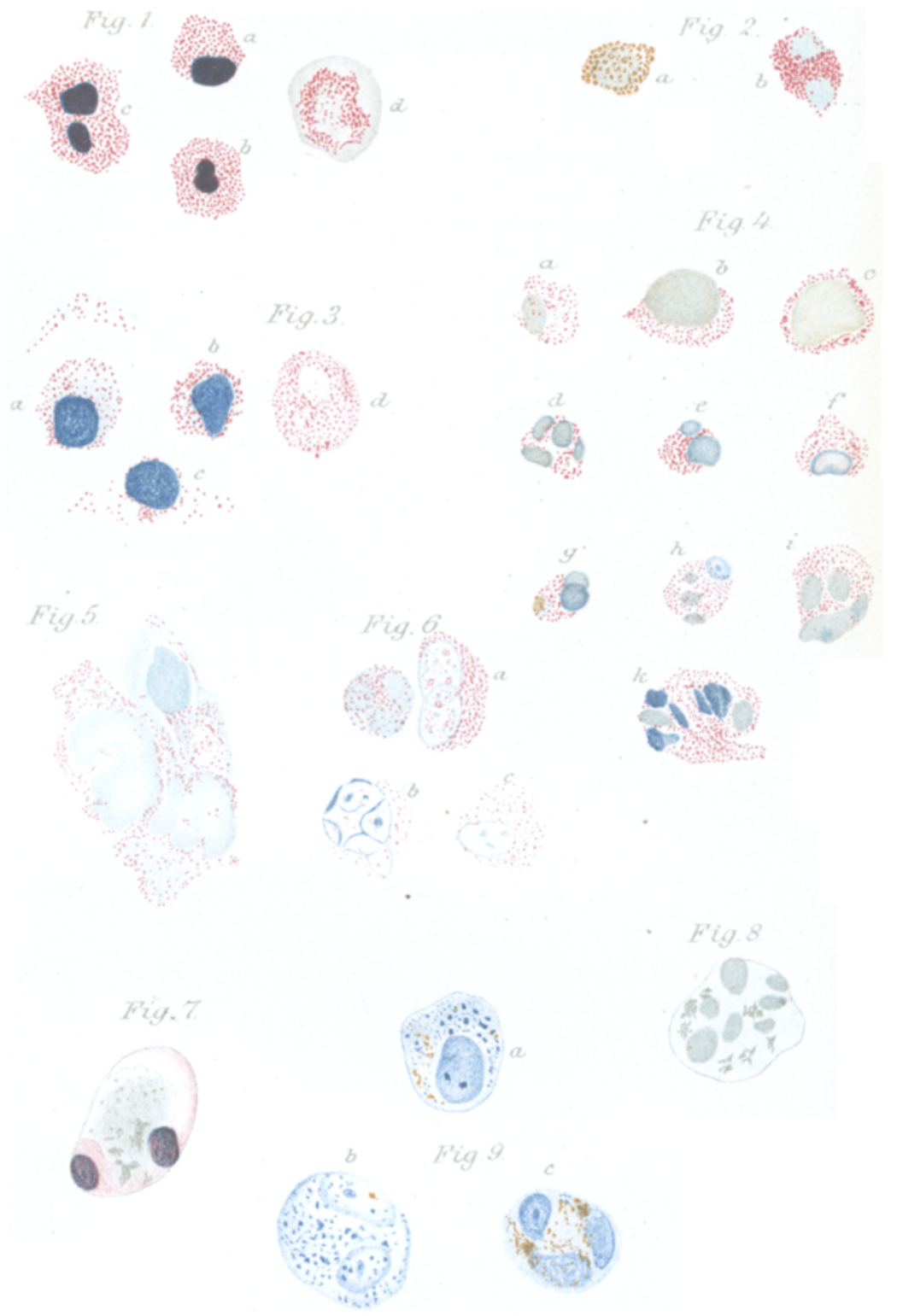


und ihren staubigen Atributen umgebenen Menschen eigenthümlich sind und fast nirgends ihre Anwesenheit vermissen lassen. Den Fehler, Ehrlich'sche Färbungen nur auf das Asthma anzuwenden, haben die späteren Untersucher zwar nicht begangen, immerhin aber konnte der mehr oder weniger negative Ausfall ihrer Befunde bei anderen Athmungs-Krankheiten um so weniger Eindruck erwecken, als dieselben nicht immer vollständig übereinstimmten. Schmidt ${ }^{3}$ sah in vier Fällen von Phthise gar keine eosinophilen Zellen, ebenso Gollasch ${ }^{3}$, während Leyden wenigstens in einem Falle eine constatiren konnte. Bei Pneumonie wurden sie nur ganz vereinzelt gefunden, gar nicht bei fötider (Gollasch) und eitriger Bronchitis (Schmidt) u. s. w. Um so auffalliger erscheint der. Befund einzelner bei frischer Gonorrhoe (Gollasch und Müller ${ }^{5}$ ), wo man doch nach Analogie mit anderem Eiter nur neutrophile Körnung hätte erwarten sollen. Auch über die Beschaffenheit der Asthma-Spiralen scheinen Gollasch's und Schmidt's. Ansichten sich nicht zu decken, da letzterer den Centralfaden nach dem Ergebniss der Thioninfärbung als Mucin anspricht, während ersterer die Spirale nur aus Eosinzellen zusammengesetzt fand. Andere Färbungen wurden nur wenig angewandt: Mastzellen konnte Fink ${ }^{6}$ nicht mit Sicherheit nachweisen, während Sohmidt uns das Vorkommen solcher bei einfacher und fibrinöser Bronchitis und Pneumonie, Lenhartz ${ }^{7}$ bei Asthma berichtet, Mabdybur ${ }^{8}$ aber basophile Zellen nur bei Asthma sab. Endlich soll nach Lenhart $z^{9}$ Angaben im asthmatischen Sputum stets basophile Körnung neben der vorwaltenden eosinophilen vorkommen. Diese verschiedenen und nicht ganz umfassenden Befunde mussten zur Nachprüfung reizen, welche in erster Reihe mit den zur Verwendung gelangten Methoden zu beginnen hatte. Denn kein Autor, mit Ausnahme von Gollasch, hatte die Art seines Vorgehens bei Dauerpräparaten angegeben, nur hie und da fand sich eine Angabe über einen verwendeten Farbstoff; es blieb nichts übrig, als anzunehmen, dass die Präparation und Färbung der Sputa in derselben Weise, wie beim Blute erfolgt sei, d. h. Fixirung durch Hitze oder Alkohol-Aether u. s. w. Vertrauensvoll und eigentlich ohne Zweifel bezüglich des Gelingens, da nirgends etwas von Schwierigkeiten berichtet war, wurde 
ebenso verfahren und - bald zeigte sich, dass hier wohl die Lösung jener Widersprüche, und ganz besonders derjenigen, welche unsere eigenen späteren Untersuchungen gegenüber den bereits vorhandenen Befunden zu Tage förderten, zu finden sei. Nicht genug, es zeigte sich schon von vornherein, dass die beim Sputum bisher übliche Methode der Fixirung und Färbung für gewisse, später zu erwähnende Befunde nur rein zufällige Ergebnisse, vor Allem aber ganz ungenügende Erhaltung der Zellstructur ergab. Scheint doch auch Lenhartz mit fixirten Präparaten kein besonderes Glück gehabt zu haben, da die auf seine Anregung von Schlüter unternommenen Färbungen „noch am schönsten an frischen Sputampräparaten ausfielen."

Es wurde nothwendig, eine Methode zu suchen, welche diese Uebelstände ausschloss, weiterhin nothwendig, die FärbungsMethoden verschiedentlich durchzuprüfen. Wenn das erzielte Ergebniss wenigstens bezüglich der Fixirung in einer lächerlich einfachen Lösung gipfelt, so wird nicht unangebracht sein, die vorher zu überwindenden Schwierigkeiten durch Schilderung der als ungenügend befundenen Verfahren darzulegen, um so mehr, als dadurch neuen Untersuchern viele vergebliche Mühe erspart werden kann. Die Ausnutzung der durch sichere Fixirung gegebenen Möglichkeit, auch anderen Zellformen, speciell jenen, welche als Fremdkörper-Zellen bezeichnet werden können, etwas näher zu treten, lag nahe. Auch über diese ist also Einiges zu berichten. Zunächst aber die

Methoden der Fixirung und Färbung.

Zur Fixirung des Sputum behufs Färbung ist dreimaliges Durchziehen durch die Flamme, zu der des Blutes Erhitzung im Brutofen auf $115-120^{\circ}$ C. angewandt worden. Beide Methoden, auch blosses Erwärmen auf $37-40^{\circ} \mathrm{C}$, während verschiedener Zeitdaner angewandt, versagten. Die Zellkerne färbten sich gut, häufig auch Granula, unter allen Uimständen aber wurde der Zellencontour zerstört, oft ausgerissen, mindestens aber zackig ausgefranzt.

Es wurde jetzt versucht, die aufgetrockneten Sputa in Sublimat, theils mit; theils ohne Kochsalz in verschiedenen 
Concentrirungen zu härten: dasselbe Resultat. Zur Fixirung mittels Alkohol-Aether übergehend, konnten wir den besagten Uebelstand auch nicht beseitigen, und besonders störend erschienen körnige Niederschläge im Schleim, welche reine Zellbilder sowohl, als sichere Färbungen nicht zu Stande kommen liessen. Gelang es wirklich einmal, annähernd rein zu fixiren, so kam es zu keiner zuverlässigen Färbung. Oft versagte die Färbung auch ganz da, wo sie am frischen Präparat rasch und tadellos gelungen war, oder eine derart schon gelungene verschwand spurlos beim Versuch, eine Doppelfärbnng (Eosin-Methylenblau u. s. w.) zu erzielen.

Die Ursache in der Umhüllung der Zellen mit dem Schleim. zu suchen, lag nahe; störte doch derselbe schon durch seine Trübung, und konnte andererseits die sonst am Eiweiss der Zellen leicht zu erzielende Härtung u. s. w. hindern, also den Schleim beseitigen: jeder Versuch hierzu mit alkalischen Lösungen (Salz, Natron- und Soda-Lösungen) schlug fehl.

Es wurde nun zur Fixirung mit Formalin-Dämpfen geschritten, indem die vorher an der Luft angetrockneten Präparate über dem Wasserbade 5 Minuten lang den Dämpfen ausgesetzt wurden. Das Verfahren brachte die ersten sicheren Ergebnisse, indem nicht nur, (was ja bisher auch schon, wenn auch unregelmässig, vorgekommen), die Färbungen gelangen, sondern vor Allem die Zellformen erhalten blieben. Aber jetzt drängte sich auch der Gedanke auf, ob denn diese geringfügige Einwirkung überhaupt noch zur Fixirung nothwendig gewesen sei; vielleicht ging es auch ohne diese, - und es war auch so. Eine nicht nur vollkommen genügende, sondern vor Allem bezüglich zu befürchtender Störungen der Formen oder der Färbbarkeit der Zellen ganz unschädliche, noch dazu allereinfachste Methode konnte von da ab angewandt werden, indem nur die auf's Feinste mittels zweier Nadeln auf dem Objectträger auseinander gezogenen oder auf demselben zartest verstrichenen Sputa durch geraume Zeit $\left(\frac{1}{2}\right.$ bis 24 Stunden) bei Zimmer-Temperatur luftrocken gemacht und dann ohne Weiteres der Färbung zugeführt wurden. Als das Wesentliche zum Gelingen aber darf die absolute Trockenheit der Objecte bezeichnet werden. Dies geht so weit, dass gut getrocknete Präparate sogar ohne Gefahr des Verderbens 
noch durch die Flamme gezogen werden können. Hier ist also das Punctum saliens sicherer Conservirung. Was am meisten gefürchtet werden musste, das Fortschwimmen der Sputa in der Farbe oder bei der Wasserspülung, trat (mit seltenen, nachher zu erwähnenden Ausnahmen) nicht ein, und so konnte jetzt sicher gefärbt werden. Angewandt wurden nun folgende Färbungen:

1. Eosin, in 1 pCt. wässr. Lösung. Lässt man dasselbe dem frischen Sputum unter dem Deckglas zufliessen, so fängt es in längstens 5 Minuten an zu färben, während eine sichere Durchfärbung aller vorhandenen Granula erst ungefähr im Verlauf einer Stunde erfolgt.

Zur Färbung angetrockneter Sputa wurde die Lösung eine Stunde lang im Standglase applicirt, dann sehr kurz mit Wasser ausgewaschen und die Kerne nachgefärbt. Die Auswaschung erfordert viel Subtilität. Zu kurzes Verfahren lässt das ganze Plasma diffus roth erscheinen, ohne dass die Körnchen sich differenziren, bei zu langem kann die Granula-Färbung zu stark abblassen. Die Stärke der Färbung scheint, abgesehen von wahrscheinlich auch wirkendem biochemischem Verhalten, besonders noch von der Schleim-Umhüllung abzuhängen. Da gerade das Eosin die Eigenthümlichkeit zeigte, den aufgetrockneten Schleim gern wieder zur liösung zu bringen, so dass also nach einstündiger Application mitunter manches vom Objectträger davon geschwommen war, wurde in solchen Fällen auch zu der Auskunft gegriffen, eine fein verstrichene Flocke auf dem Objectträger direct mit Eosin-Lösung zu begiessen und so nach einiger Zeit antrocknen zu lassen. Die auf diese Weise behandelten Zellen verloren aber ihre Körnchen-Färbung sehr gern wieder beim Auswaschen oder Nachfärben, am wenigsten noch jene des asthmatischen Auswurfes einige Tage nach dem Aufall, ein Umstand, der bereits einiges Licht auf die bisherigen Befunde wirft. Daher schwankten auch unsere Resultate so lange, bis gelernt wurde, durch sehr sorgfältiges Trocken-Fixiren jenen Uebelstand zu vermeiden: alle einmal eine Stunde lang in Eosin gefärbten Granula blieben gefärbt. Wo Schwankungen vorkamen, blieb noch die Controle mit frischer Eosin-Färbung, Triacid und Neutralfarbe. 
2. Ehrlichs Färbung für. a-Granula (Eosin-Aurantia-Nigrosin in dreifacher Glycerin-Mischung).

3. Ehrlich's Glycerin-Eosin, nach Vorschrift angewendet.

4. Ehrlich's Färbung für $\gamma$-Granula in Mastzellen.

5. Essigsaures Thionin (1 ccm einer 1 procentigen, in kochendem Wasser hergestellten Lösung auf $30 \mathrm{ccm} \ddot{z}$ procentiger Essigsäure), 5 Minuten angewendet für $\gamma$ - und $\delta$-Granula.

6. Methylenblau in verdünnter wässriger Lösung, 5 Minuten lang zur Färbung basophiler ( $\hat{o}^{-}$) Granula aufgetragen.

7. Ehrlich's Färbung für neutrophile (s-) Granula (Säurefuchsin-Methylenblau-Mischung).

8. Berganzini's Dreifarbengemisch, für $\alpha$ - und $\varepsilon$-Granula.

9. Ehrlich's Triacid, 6 Minuten applicirt, für $\alpha-(\gamma-)$ and \&-Granula.

10. Methylenblau in concentrirter Wasserlösung, einige Secunden aufgetragen, zur Kernfärbung.

11. Alaun-Hämatoxylin, $\frac{1}{4}$ bis $\frac{1}{2}$ Minute und

12. Ehrlich's saures Hämatoxylin, 2 Minuten wirkend.

13. Mit Sudan in alkoholischer Lösung wurde in einigen Fällen der Nachweis von Fett versucht. Da der Farbstoff, wie in allen wässrigen Lösungen, auch bei Berübrung mit dem Wasser des Sputum sich in feinsten Körnchen oder grösseren, FettsäureNadeln ähnlichen Krystallen niederschlägt, so wurde nur angetrocknetes Sputum gefärbt und mit verdünntem Alkohol nachgewaschen, dann in Canadabalsam conservirt.

14. Als Controlfärbung für Bacterien kam noch Fuchsin in Betracht, da mit Methylenblau gefärbte Bacterien zu Verwechslungen mit Granula Anlass geben könnten.

Schnitte von Sputum und Lungengewebe wurden mit EosinMethylenblau, mit Böhmer's. Hämatoxylin und Alauncarmin in üblicher Weise gefärbt, theilweise auch mit Triacid, welches ganz vorzügliche Contrastbilder lieferte. Auch hier wurde 6 Minuten lang gefärbt, dann reichlich mit Wasser und 60 pCt. Alkohol nachgewaschen. -

Bevor nun auf die mit diesen Färbungen, welche sich im Wesentlichen auf die Erforschung des Zellplasma richteten, erzielten Einzelresultate näher eingegangen wird, soll hier gleich 
vorgreifend bemerkt werden, dass in den Zellen sowohl des Auswurfes, als des Eiters vornehmlich zwei Arten von Körnchen im Plasma angetroffen wurden, welche sich, ausser der morphologischen Verschiedenheit, auch wesentlich different gegen die oben erwähnten Farbstoffe verhielten: Erstens eine Form grober und bei wechselnder Einstellung bald ringförmiger, bald compacter Körnchen, welche die Zelle ausserhalb des Kernes so dicht erfüllen, dass vom Plasma sonst gar nichts zu sehen ist. Mit Eosin gefärbt, erschienen sie intensiv glänzend carminroth (Fig. 1). Nachfärbungen sowohl mit saurem, als mit alkalischem Hämatoxylin and Methylenblau ändern daran nichts. In Triacid erscheinen diese Granula gelbroth (Fig. 2a). - Zweitens etwas feinere Granula, mitunter dünner gesät und einen Theil des Plasma durchschimmern lassend, auch wohl ganz verstreut, aber häufig auch den oder die Kerne überlagernd. Auch diese Körnchen färben sich mit Eosin schön carminroth. Färbt man mit Alaun-Hämatoxylin nach, so erhält sich die Färbung nicht immer, besser bei vorsichtiger Nachfärbung mit Methylenblau (Fig. 3). Wird aber letzteres nur ein wenig zu lange angebracht, so tritt eine Ueberfärbung der Granula mit blauem Ton ein. In Triacid färben sie sich im Gegensatz zum Gelbroth der anderen schön carminroth, treten hier auch besonders feinkörnig und klar hervor (Fig. 4). Hämatoxylin-Eosin nach Ehrlich lässt sie bloss rosaroth erscheinen. Färbt man die mit Eosin oder Triacid gefärbten Granula noch mit saurem Hämatoxylin nach, so verschwinden sie sofort, ebenso wenn man vor dem Färben mit Essigsäure behandelt.

In Berganzini's Lösung erschienen die Kerne hellgrünblau, die Granula blass graugelb. In Ehrlich's Neutral-Farbengemisch wurden diese Granula mit zwei Ausnahmen gar nicht gefärbt, mit Ehrlich's Farbe für $\alpha$-Granula nur einmal. Fragen wir nun nach der Natur der erstbeschriebenen Gebilde, so erweisen sowohl die grobe Beschaffenheit der Körner, als ihre Farb-Reaction im Einklang mit ihrer Säure-Beständigkeit ihre Identität mit den gewöhnlichen eosinophilen Granula des Blutes. Die zweite Varietät aber entspricht keiner der bisher beim Menschen im Blut oder Auswurf u. s. w. beschriebenen Körnchenarten. Ihr Aussehen in ungefärbtem Zustande ent- 
spricht allerdings ungefäbr den neutrophilen s-Körnchen, aber sie färben sich anders: während sie mit den für $\varepsilon$-Granula charakteristischen Earben in Ehrlich's Neutralgemisch, Triacid und Berganzini's Farbe nicht tingirt werden, nehmen sie ohne weiteres Eosinroth an. Von den eosinophilen aber unterscheiden sie sich wiederum durch geringere, bezw. andere Färbbarkeit in Bergazini'scher Mischung, Hämatoxylin-Eosin und Triacid, sowie durch die Entfärbung unter dem kurzen Einfluss von Essigsäure und längerer Einwirkung von Alkalien (Alaun-Hämatoxylin und Methylenblau). Sie sind somit auch nicht strict als eosinophil anzusehen. Stimmen sie sonach nicht mit den bekannten Granula menschlicher Zellen überein, so scheinen sie umsomehr Aehnlichkeit mit Körnchen zu besitzen, welche, nach einer Mittheilung von Ehrlich ${ }^{10}$, Kurl off im Blute vom Meerschweinchen, Ehrlich selbst schon früher bei Kaninchen gefunden hat. Aber identisch sind sie mit diesen auch nicht. Während die Ehrlich-Kurloff'schen Granula nur in multinucleären Leukocyten vorkommen, finden sich die beschriebenen auch in uninucleären Zellen; ebenso ist die Widerstandsfähigkeit unserer Granula gegen alkalische Lösungen entschieden ebenfalls vermindert im Gegensatz zu jenen, die nur sauren Lösungen erliegen.

Die Eigenthümlichkeit der von mir gefundenen Körnchen besteht also im Wesentlichen in einer Eosinophilie verminderten Grades, so dass ihre Bezeichnung als "hy poe osinophile" gerechtfertigt erscheint.

Ausser diesen zwei typischen Arten kamen nun noch einige in Form und Färbbarkeit sich anders verhaltende Gattungen von Körnchen vor, welche an ihrem Orte genauer erwähnt werden. $W_{0}$ in den folgenden Berichten von eosinophiler und hypoeosinophiler Granulirung die Rede ist, handelt es sich immer um ein dem eben geschilderten ganz gleiches Verhalten.

$$
\text { 1. Rundzellen. }
$$

Um nicht zu präjudiciren, wird im Folgenden für die lenkocytenähnlichen Zellen ohne Rücksicht auf ihre Gestalt der Ausdruck "Rundzellen" gebraucht. - Wir lassen nun unsere Beobachtungen nach Krankheitsarten gruppirt folgen. 
I. Asthma bronchiale.

Die bei uns sehr seltene Krankheit kam nur in zwei Fällen zur Beobachtung, wovon auch nur der erste sicher gestellt erscheint.

1. Der erste Fall zeigte in wässrig-schleimigem Substrat kleinste gelbweisse Schleimballen und weisse Fetzchen. Erstere enthielten ausschliesslich, wenn auch nur zeitweise, gewöhnlich 1-2 Tage nach den Anfällen, Spiralen. Die Substanz dieser Gebilde ist sowohl als Fibrin, wie als Mucin angesprochen worden. Schmidt ${ }^{2}$ sieht insbesondere den Centralfaden als Mucin an, da derselbe sich mit den specifischen Färbemitteln des Schleims, Thionin und Triacid (mit letzterem grün), färbe. Allgemeingültigkeit für jedes Stadium der Spiralenbildung kommt diesem Befunde wohl nicht zu: es ist ja sehr schwer, die meist nicht dünnen spiralförmigen Gebilde durchzufärben, sofern dies nicht im Schnitt geschieht, - (und gegen letzteres Verfahren spricht die Verletzbarkeit der Granula durch das Härtungs- und BettungsVerfahren) --, ohne dass die Structur undeutlich wird; aber es gelingt doch, sehr dünne Spiralen derart am Objectträger auszubreiten und anzutrocknen, dass beide Erfordernisse erfüllt werden. Färbungen mit Triacid sowohl, als mit Eosin und saurem Hämatoxylin ergaben dann, dass der ganze Spiralfaden aus Rundzellen bestand. Nur ein sehr derber Theil im Centrum der Spirale blieb undurchsichtig, bestand jedoch wahrscheinlich auch aus Zellen, da er im Triacid dunkelblau erschien.

Die weissen Fetzchen bestanden fast ausschliesslich aus Rundzellen, deren Kerne schon ohne Zusatz deutlich sichtbar waren; das Plasma wimmelt von kleinsten, stark lichtbrechenden Körnchen in lebhaftester oscillirender Bewegung; ebensolche Körnehen lagen massenhaft frei im Gesichtsfeld. Sonst waren nur wenige grössere polygonale Plattenepithelien und etwas mehr mit braunem bis schwarzem Pigment erfüllte oblonge Zellen von etwa doppelter Grösse der Rundzellen mit excentrischem Kern sichtbar, daneben etwas freies dunkles Pigment in Schollen.

Frisch mit Eosin gefärbt, zeigen sich in einer grösseren Anzahl der Zellen lebhaft rothe Granula, während andere theils eine diffuse, theils gar keine Plasma-Färbung darbieten. Auch freie Granula zeigen sich massenhaft in rother Farbe. An fixirten 
Präparaten dasselbe Eigebniss, nur dass gute Triacidfärbung überhaupt keine Rundzellen frei von Granula zeigt. Die Mehrzahl der Zellen ist mehrkernig und locker gefüllt mit bypoeosinophilen, feinen Granula, während in ziemlich erheblicher Anzahl, meist ein-, selten zweikernige Zellen das Plasma gestopft voll von groben, säurebeständigen, eosinophilen Granula zeigen. Das Plasma der pigmentirten grösseren Zellen dagegen ist auch am Trockenpräparat nur diffus geröthet, ohne Körnung, mit sichtbarem, feingenetztem Gerüst. Eine Anzahl ganz gleicher Zellen enthält Pigment, jedoch vereinzelte hypoeosinophile Granula, welche den Eindruck machen, als ob nach ihrem Verschwinden ein ebensolches feines Gerüst überbleiben müsste, wie in den pigmentirten.

2. Von einem zweiten Falle erhielt ich nur ein spärliches, weisses, zähes Sputum ohne Spiralen. Asthma-Anfälle sollen beobachtet worden sein. Es bestand wiederum aus PflasterEpithel und viel Rundzellen. Frisch gefärbt zeigen sich nur wenige hypoeosionophile Granula in einzelnen Zellen, trocken dagegen massenhaft solche, auch freiliegend.

\section{Bronchitis simplex.}

3. Reichlich eitrig-schleimiges, geballtes Sputum, ohne Tuberkelbacillen. Besteht nur aus dichtgedrängten Rundzellen mit ein bis fünf Kernen. In sämmtlichen hypoeosinophile Granula, freiliegend wenige, hie und da ein freier Kern, ziemlich reichlich freies schwarzes Pigment in grossen Schollen und kleinsten Körnchen.

4. Gelbgrüne Eiterschleimballen. Dichtgedrängte Rundzellen, ein- bis fünfkernig, durchweg mit hypoeosinophilen Granula gefüllt, wenige solche freiliegend. Hie und da eine drei bis viermal so grosse ovale Zelle mit rundzellengrossem Kern, schwarzes Pigment enthaltend, ohne Granula.

5. Gelbgrüne Eiterschleimballen, auch einzeln Schleimfäden. Durchweg nur Rundzellen, deren Kerne schon in frischem Zastande sehr gut sichtbar sind. 1-4 Kerne, Plasma gestopft voll hypoeosinophiler Granula, wenig freiliegende; der Kern der einkernigen Zellen zeichnet sich durch besondere Grösse aus. Pigmentirte Zellen wie oben mit 1-2 Kernen. Hie und da 
kleine Gruppen einkerniger, mässig grobgranulirter eosinophiler Zellen.

6. Schleimiges Sputum mit reichlichen, geballten, eitrigen Beimengungen. Dichtgedrängte Rundzellen, ungefärbt schov starke Körnchenbildung zeigend, wie beim Asthma. Das Plasma der durchweg hypoeosinophile Granula enthaltenden Rundzellen ist meistens undeutlich begrenzt, viele freie Granula sichtbar. Selten kleine Staubzellen ohne Granula mit wandständigem Kern und ebenso grosse ovale, nicht pigmentirte Zellen mit centralem Kern.

III. Bronchitis foetida.

7. Furchtbar stinkender, sich schichtender Auswurf, flüssig, gelbgrün. Dichtgedrängte Rundzellen, selten ein grosses Plattenepithel. Sämmtliche Rundzellen sind überfüllt mit hypoeosinophilen Granula, massenhaft liegen auch solche im Freien. Die meisten Zellen sind zweikernig. Hie und da eine grob granulirte, eosinophile, zweikernige Zelle.

\section{Phthisis.}

8. Graugelbliches, dünnes, durchscheinendes und fetziges Sputum. Die Rundzellen zeigen schon ungefärbt Gravulirung. Dieselbe erweist sich als hypoeosinophil, allerdings ziemlich ungleichmässig. Die Zellen sind meist zweikernig, viele 3-5kernig, sehr wenige haben nur einen Kern. Ganz selten einige säurebeständige, fein granulirte, eosinophile Zellen, ein- und mehrkernig. Gruppenweise finden sich ovale mit schwarzem feinem Pigment in sehr verschiedener Quantität gefüllte Zellen vor, meist ein-, selten zweikernig, in der Grösse meistens die Rundzellen nur um weniges übertreffend, mit wandständigem Kern; ausserdem grosse polygonale und kleinere ovale Epithelien mit centralem Kern.

9. Spärlicher schleimiger Auswurf in dünnen, weissgelben, zähen Ballen. Schon frisch deutliche Körnung sichtbar, welche in Färbung sich als hypoeosinophil erweist. Einzelne Zellen von gleicher Grösse, wie die Rundzellen, und mit ebenso grossem Kern führen fein vertheiltes, schwarzes Pigment; ihr Plasma ist blass und nicht granulirt. Dieselben unterscheiden sich deutlich von benachbarten, grossen, ovalen und polygonalen Zellen mit Kernen 
von der Grösse ganzer Rundzellen, offenbar Epithelien der oberen Luftwege.

10. Massenhafte, münzenförmige, gelbgrüne Spata. Die meist einkernigen Rundzellen sind in einem sehr dichten Schleimstratum eingebettet; ihr Plasma, ebenso wie dieses Stratum, ist dicht mit hypoeosinophilen Granula erfüllt. Wenig mittelgrosses Epithel.

11. Zäher, glasiger, graugelber Auswurf, theilweise leicht himbeerfarbig. Viele rothe Blutkörperchen, zahlreiche lebhaft granulirte mittelgrosse Rundzellen; die Körnung ist durchweg hypoeosinophil. Freiliegende Granula zahlreich. Vereinzelte eosinophile feingranulirte Zellen.

12. Gelbe, münzenförmige Ballen, bestehend aus dichtliegenden, stark granulirten Rundzellen. Die Körnung ist hypoeosinophil, das Schleimstratum ebenfalls von solchen Granula erfüllt. Die Contouren vieler Zellen sind nicht klar abgegrenzt, die Körnchen treten vielfach darüber hinaus. Freie Kerne nicht sichtbar.

13. Reichliches flüssig-schaumiges Sputum mit vielen gelbgrünen Ballen und weisslichen "Linsen". In letzteren finden sich neben mässig vielen, hypoeosinophil gekörnten Rundzelllen viele, sehr grosse Platten-Epithelien, deren Kern, so gross wie die ganzen Rundzellen, in Methylenblau lebhaft gekörnt erscheint, während der blasse Zellleib oft so verschwimmt, dass man bei oberflächlicher Betrachtung den Kern für eine basophil granulirte Zelle halten könnte. Kerne und hypoeosinophil gekörnte Plasmafetzen sieht man zahlreich frei daliegen.

\section{Pneumonie.}

14. Derber, gelber Fetzen mit röthlichen Streifen. Die Rundzellen sind meist ein-, selten mehrkernig, durchweg im Plasma hypoeosinophil granulirt. Hie und da freiliegende Kerne und Plasmaschollen. Viele freie, hypoeosinophile Granula. Wenige rothe Blutkörperchen, an einigen Stellen grosse Platten-Epithelien. Ziemlich viel freiliegendes, gekörntes, schwarzes und dunkelbraunes Pigment.

15. 8. Tag. Zähes, bernsteinfarben durchscheinendes, spärliches Sputum. Daneben einige reich verzweigte Fibrin-Gerinnsel. In der Hauptsache mittelgrosse, stark gekörnte Rundzellen, 
wenig Erythrocyten, einige etwas grössere, ovale Zellen mit dunkelbraunem Pigment erfüllt, welches sich auf Zusatz von Ferrocyankalium und Salzsäure blau färbt. Einiges freies, schwarzes Pigment. Die Rundzellen führen auffallend viele, bis zu 6 Kernen, haben theilweise auch eine langgestreckte Figur angenommed; ihr Plasma ist reichlich hypoeosinophil granulirt, das der pigmentirten Zellen blass und nicht gekörnt.

16. 6. Tag. Zähes, diffus geröthetes Sputum. Viele Erythro-, wenig Leukocyten. Einzelne, nur wenig grössere pigmentirte Zellen ohne Hämosiderin-Reaction.

17. Abgelaufene Pneumonie. Reichliches, schleimiges, graues Sputum mit kleinen Blutfleckchen, enthält dicht gelagerte, gleichmässig grosse Rundzellen, durchweg mit hypoeosinophilen Granula.

18. 3.-4. Tag. Rothgelbliches, durchscheinendes Sputum mit kleineren Blut-Einlagerungen. Letztere zeigen fast nur rothe, sehr wenig weisse Zellen mit hypoeosinophilen Granula, viele pigmentirte Zellen von $1 \frac{1}{2}$ facher bis doppelter Grösse, ohne Eisen-Reaction.

19. Spärlicher, rostfarbener, dünner Auswurf, dazwischen fibrinöse Bronchial-Abgüsse in ziemlicher Ausdebnung. Die Rundzellen zeigen Körnung in auffallender Verschiedenheit. Während einzelne geradezu gepfropft voll sind, so dass in der rothen Grundlage kaum die einzelnen Körner sich differenziren lassen, zeigt die Mehrzahl jene zarte Granulirung, wie sie sonst fast überall beobachtet wird, hie und da so dürftig, dass man sie nur mit Mühe bemerkt. Endlich ist auch eine Reihe gar nicht granulirter Zellen zu bemerken. Im Zusammenhang, besonders mit den letztgeschilderten, erwecken sie den Eindruck, als ob die Granulirung wohl auch in ihnen bestanden habe und nur zeitweilig verschwunden sei. Die ein- bis zweikernigen, dicht und gröber granulirten haben im Triacid einen etwas lichteren Farbenton (Fig. 2 b), als die feingranulirten, so dass sie wohl als ächte eosinophile anzusprechen sind, wenn sie auch nicht das sonst gewohnte Gelbroth zeigen, während die auderen auch in der Farbe den sonstigen hypoeosinophilen Körnchen gleichen. Ziemlich häufig sieht man mit feinem Staub-Pigment zart gefüllte, oft sehr grosse, blasse Zellen mit ein bis sechs centralen Kernen. 
20. Abgelaufene Entzündung. Gelbgraues spärliches Sputum Die Rundzellen sind meist 2-3 kernig, ausnahmslos stark hypoeosinophil gekörnt, ganz vereinzelt in dickster Menge. Viel freie Granula. In nicht unbeträchtlicher Anzahl sind pigmentirte, nicht granulirte Zellen, meist einkernig mit excentrischem Kern, selten zweikernig, vorhanden, in der Grösse mitunter die Rundzellen nur wenig übertreffend, aber auch bis zum doppelten Flächenraum. Ziemlich viel freies, gröberes, schwarzes Pigment. Sämmtliches Pigment gibt keine Eisen-Reaction.

21. Abgelaufene Entzündung. Zäh-glasiger, durchscheinender Auswurf mit reichlichen braunrothen Einlagerungen. Wenig rothe Blutkörperchen; die zahlreichen Rundzellen sind zumeist einkernig, doch vielfach auch 2-4 kernig, und zeigen schon frisch ausserordentlich reiche Körnung. Diese erweist sich gefärbt als hypoeosinophil. Hie und da einige fein pigmentirte, grosse, ovale Zellen mit excentrischem Kern.

22. Entzündung im Gefolge von Influenza. 5. Tag. Reichliche, gelbgrüne, lockere Ballen. Viel Detritus, zahlreiche polygonale, grosse Epithelien, einzelne ovale bis runde kleinere, mit grossen Kernen (Alveolar-Epithel?), sämmtlich mit centralem Kern. Die Rundzellen sind fast alle mehrkernig und alle hypoeosinophil.

Auch in einer Anzahl von Sputa nicht besonders an den Luftwegen erkrankter, beziehungsweise herzkranker Personen wurden grösstentheils die Rundzellen untersucht, meist mit dem gleichen oder ähnlichen Ergebniss, wie bisher berichtet. Da das Interesse bei diesen Sputa aber mehr an den pigmentirten Zellen haftet, wird über diese Befunde erst weiter unten im Zusammenhange (Fall 64-76) berichtet. Im Allgemeinen waltet auch dort die hypoeosinophile Granulirung ob.

Die Erage, ob diese bemerkenswerthen Eigenthümlichkeiten etwa nur den Producten der Alveolen und der BronchialSchleimhaut zukommen, veraulasste mich, zunächst gleichartigen schleimhaltigen Auswurf von anderen Stellen zu untersuchen. Dazu bot sich zunächst das Secret der Nase und ihrer Nebenhöhlen. 


\section{Nase.}

23. Glasig-schleimiges Secret bei Hypertrophie der Rachenmandel, nach vorn ausgeschneuzt. Keine Epithelien, die zahlreichen Rundzellen alle mehrkernig, theilweise langgezogen, andere confluirt und in der Auflösung begriffen (Fig. 5), lebhaft hypeosinophil granulirt. Viele freie, rothe Granula. Hie und da kleine Gruppen eosinophiler, feingranulirter Zellen mit (in Triacid) gegenüber den anderen auffallend blassen grünblauen Kernen. Einiges freiliegendes, gelbes bis braunes Pigment.

24. Glasiges, schwärzlich gesprenkeltes Secret der Nase, chronischer Katarrh. Zahlreiche mittelgrosse Randzellen, einbis vierkernig, sehr schwach hypeosinophil gekörnt, wenige freie Granula. Hie und da eine zerfallene eosinophile Zelle. Ziemlich viel gelbbraunes, scholliges Pigment liegt frei da. Hie und da mittelgrosse polygonale Epithelien.

25. Subacuter Schnupfen. Spärliches, wässrig-schleimiges Secret mit dünnen, braunen Streifen. Ziemlich reichlich braune bis gelbe Schollen, mässig viele Rundzellen mit hypeosinophiler Körnung, einige etwas langgezogen.

26. Chronisch vermehrtes Nasensecret. Glasiger Schleim mit braungelben Streifen. Viel freies, scholliges, gelbes bis schwarzes Pigment, wenig, meist mehrkernige Rundzellen, theilweise etwas länglich, hypeosinophil, doch sehr schlecht färbbar.

27. Heftiger acuter Schnupfen. Reichliches, ganz wässeriges, doch fadenziehendes Secret. Die Antrocknung gelingt ausserordentlich schwer. Während sonst der Auswurf in längstens einer Stunde angetrocknet ist, erscheint dieser nach zwei bis drei Tagen noch feucht, sodass mit Wärme nachgeholfen werden muss. Kein Flimmer-Epithel, dagegen stellenweise ziemlich viele grosse Platten-Epithelien. An einzelnen Stellen Häufchen von Rundzellen in spärlichen Schleim eingebettet, meist mehrkernig, durchweg hypeosinophil, doch schlecht färbbar. Weiterhin Gruppen von doppelt bis dreifach so grossen, ovalen Zellen, mit ein- bis drei wandständigen, grossen Kernen und blassem, netzförmigem Plasma, welche gelbes bis braunes, kleinscholliges Staub-Pigment enthalten.

VII. Nebenhöhlen.

28. Aus einer Kieferhöhle durch Ausspülen nach Punction Archiv f. patbol. Anat. 158. Bd. Hft. 2. 
entleert: Glasiger Schleim mit dünnen, weissgelblichen, opaken Streifen. Letztere bestehen aus dichtgedrängten Rundzellen in einer ausserordentlich spärlichen Schleimschicht, theils, etwa zur Hälfte, aus kleineren ovalen, welch' letztere bereits ganz frisch erscheinen. In Triacid-Färbung zeigen die ersteren feine carminrothe Granulirung, während die anderen grobe, gelbrothe, dichtgedrängte Granula in etwas blasserer, als der sonst gewohnten Färbung enthalten. Mit Eosin gefärbt und saurem Hämatoxylin nachbehandelt, erscheinen die ersteren Zellen im Plasma blassrosa mit hie und da vorhandener Andeutung körniger Differenzirung, die anderen haben ein tiefrothes Plasma ohne Körnung. Nicht selten sieht man grosse Schollen conglobirter und sich auflösender Kerne, und hier finden sich roth gefärbte und typisch geformte Granula in kleinen Häufchen. Selten einmal eine roth und grob granulirte Zelle.

Die feinen Granula sind also als gewöhnliche hypeosinophile anzusprechen, die wenigen eingeschlossenen und die freien säurebeständigen als typisch eosinophil, die groben Granula dagegen als eine Art $Z$ wischenstufe $z$ wischen beiden, da sie wohl nach ihrer Färbbarkeit in Triacid und Form den gewöhnlichen gleichen, aber nicht säurebeständig sind.

29. Aus einer Kieferhöhle direct entleerter, gelb durchscheinender Schleimballen. Ziemlich zahlreiche, meist mehrkernige Rundzellen, durchweg in Triacid roth gefärbt. In Hämatoxylin-Eosin und Ehrlich's $\alpha$-Farbengemisch nehmen die Granula die Färbung eosinophiler an, von denen sie sich aber ausser ihrer Triacid-Reaction durch spärlichere Lagerung und Feinheit unterscheiden.

30. Gelber, wenig schleimiger, lockerer Ballen aus einer Kieferböhle. Die zahlreichen, meist mehrkernigen Rundzellen zeigen aussergewöhnlich reiche und dichte hypeosinophile Körnung, auch reichlich freiliegend. Ganz selten eine grobgranulirte eosinophile zweikernige Zelle.

31. Zäher, gelber, schleimiger Ballen aus einer Kieferhöhle. Die viel- (4-7) kernigen Rundzellen sind, ausnahmslos, reichlich hypeosinophil feingranulirt, auch viele freie Granula vorhanden.

32. Blassgelblich brauner, zasammenhängender Schleim- 
klumpen mit kleinen braunrothen, fleischfaserartig aussehenden Einlagerungen, aus einer Kieferhöhle. Die letzteren bestehen aus massenhaftem, braungelbem Detritus und einzelnen mit gleichartigen Körnchen gefüllten Rundzellen. Die Partikel geben mit Ferrocyankalium und Salzsäure keine Eisen-Reaction. Die Rundzellen sind meist mehrkernig und führen spärliche feine und schlecht färbbare, hypeosinophile Granula, welche in Eosin sehr blass bleiben, in Triacid einen Stich ins Violette haben, jedoch mit Neutralfärbung sich nicht färben. Einige Zellen haben kleine Vacuolen in den Kernen, ziemlich viele sind langgestreckt mit reihenförmig angeordneten Kernen; mitunter ein hufeisenförmiger Kern.

33. Geformter, gelber Schleim-Eiterballen aus einer Kieferhöhle. Ziemlich viele geschwänzte Flimmerzellen. Die Rundzellen sind vielfach langgestreckt, meist mehrkernig und fein hypeosinophil granulirt. Hie und da eine grob eosinophil gekörnte Zelle und Häufchen ebensolcher Granula um Zellreste herum. Hie und da auch eine Zelle mit hufeisenförmigem Kern.

34. Gelber Schleim-Eiterballen aus einer Kieferhöhle. Die mehrkernigen Rundzellen sind durchweg hypeosinophil fein gekörnt. Mässig viele freie Granula.

35. Flüssiger Eiter aus einer Stirnhöhle. Die Rundzellen liegen in einer sehr dichten Zwischen-Substanz von Schleim, führen meist mehrere, bis fünf, kleine Kerne, bie und da von Hufeisenform, selten einen grossen Kern. Ausserordentlich reichlich finden sich in denselben, sowie ausserhalb hypeosinophile Granula, im Allgemeinen feinkörnig, doch von verschiedener Stärke.

Unsere Untersuchungen führten nun von der Schleimhaut der Luftwege zu denen des übrigen Körpers über.

\section{Conjunctiva.}

36. Ektropion bei einem alten Mann, mit wässrigem Katarrh. Neben den reichlich vorhandenen grossen Plattenepithelien hie und da eine meist langgestreckte multinucleäre Bindegewebszelle mit foinen hypeosinophilen Körnchen. Wenig freiliegende.

37. Ektropion bei einem alten Mann. Starker eitriger Katarrh. Mit Eosin frisch gefärbt kein sicheres Ergebniss. Am Trockenpräparat ausserordentlich dichtgedrängte, meist runde, 
häufig auch langgestreckte multinucleäre Zellen, gefüllt mit feinen, durchweg hypeosinophilen Granulis, von denen auch viele frei liegen. Zahlreich sieht man Gebilde, welche offenbar DegenerationsVorgängen der Zellen entsprechen, nehmlich Kerne, welche in Triacid sich nicht gleichmässig blass, wie die anderen durchfärben, sondern um einen nur hie und da mit stärkeren Farbflecken gesprenkelten, sonst ganz blassen Körper einen schärfer gefärbten Rand zeigen (Fig. 6a), während die Granula entschieden b]ässer, als bei den intacten Zellen sind. Die Entartung zeigt sich am besten daran, dass viele dieser Gebilde nicht mehr die festen Contouren ganzer Zellen darbieten, sondern nur mehr aus einem derartigen kernähnlichen Gebilde mit anhängender Körnchenmasse bestehen. (Fig. 6, b u. c.).

VIII. Harnröhren-Schleimhaut.

38. Gonorrhö̈. Zahlreiche Gonokokken, meist freiliegend, wenig kleines Plattenepithel, dichtliegende Rundzellen, meist mehrkernig, stark mit feinen hypeosinophilen Körnchen gefüllt, von denen auch massenhafte das dichte Schleimstratum durchsetzen; ganz selten eine grobgranulirte (eosinophile) Zelle.

39. Gonorrhoë. Zahlreiche Gonokokken, meist in Zellen eingeschlossen. Wenig rothe Blutkörperchen; die meist mehrkernigen Rundzellen reichlich hypeosinophil fein granulirt; wenig einkernige, feingranulirte, eosinophile Zellen.

40. Gonorrhoë. Dichtes Lager multinucleärer Zellen mit feinen, dichtstehenden, hypeosinophilen Granulis, welche sich auch in Neutralfarben-Mischung roth färben. Viel freie Granula. Ziemlich viel grosse polygonale and kleine runde Epithelien.

41. Gonorrhoë. Fast dasselbe Bild, nur dass die rothe Färbung im Neutralgemisch etwas blässer ausfält. In sämmtlichen Präparaten nur eine zweikernige Zelle mit groben Granulis, welche als eosinophil mit Sicherheit anzusprechen deshalb nicht möglich ist, weil sie in einem mit Eosin-Methylenblau angefertigten Präparat sich vorfindet.

IX. Blasenschleimhaut.

42-44. In drei Fällen von Cystitis liess sich mit keiner Methode in den Zellen irgendwelche Granulirung nachweisen, nur im letzten Falle sah man vereinzelte hypeosinophile Granula auf Zellen liegen. 
Beschränkte sich nach diesen Ergebnissen das Vorkommen der eigenthümlichen Granulabildung nicht auf die Absonderungen der Luftwege, sondern liess sich auf allen Arten von Schleimhäuten nachweisen (die Ausnahme bei Cystitis ist wohl nicht zu ernst zu nehmen, in Aubetracht des Einflusses des Urins auf den Zellinhalt ${ }^{1}$ ), so fragte es sich, ob denn nicht schliesslich auch die Zellen der Secrete, welche nichts mit Schleimhäuten zu thun haben, die fraglichen Gebilde enthalten könnten. Es bandelt sich zunächst um

X. Exsudate in serösen Höhlen.

45. Seröses Pleura-Exsudat, mit sehr wenig Zellen, die meisten davon sind rothe Blutkörperchen, die anderen einkernige Rundzellen. Granula nicht nachweisbar.

46. Hämorrhagisch-seröses Pleura-Exsudat. In den spärlichen Rundzellen keine Granula nachweisbar.

47. Hämorrhagisches Empyem der Pleura. Die meist 2-3kernigen zahlreichen Rundzellen lassen keine Granulabildung erkennen. - Diese drei Exsudate waren theils mittels Wärme, theils mit Alkohol-Aether fixirt worden. Um etwaige schädliche Einflüsse dieses Verfahrens auszuschalten, wurden die zwei folgenden Exsudate nur durch Antrocknen, genau wie beim Sputum conservirt. Sofort ein anderes Ergebniss:

48. Empyem der Pleura. Die meist zwei-, seltener dreikernigen Rundzellen sind ausnahmslos dicht mit grösstentheils feinen, doch auch etwas gröberen hypeosinophilen Granulis, die anch reichlich im Zwischen-Stratum lagern, gefüllt.

49. Empyem des Pericard. Dünnflüssiger Eiter. Die zweibis mehrkernigen Rundzellen sind reichlich hypeosinophil, meistens fein, doch auch etwas gröber granulirt. Wenig freiliegende Granula.

Aehnelten diese eitrigen Exsudate schon sehr dem gewöhnlichen Gewebseiter, so war wohl auch von diesem zu erwarten, dass seine Zellen sich nicht zu different verhalten würden.

XI. Gewebseiter.

50. Eiter aus einem Ohrfurunkel. Das Plasma der spärlich

2) Dieser war direct zu erweisen, denn mit Urin behandeltes, angetrocknetes Sputum, dessen Granula vorher exquisite Eosinfürbung angenommen hatten, liess jetzt solche nur webr ganz blass und verschwommen erscheinen. 
vorhandenen ein- bis mehrkernigen Rundzellen ist dicht mit feinen hypeosinophilen Granulis gefüllt. Zahlreiche zellgrosse und -förmige Häufchen von ebensolchen Granulis ohne Kerne entsprechen jedenfalls degenerirten, in Auflösung begriffenen Zellen.

51. Eiter aus einem Mamma-Abscess. Die Rundzellen sind meist mehrkernig, ihr Plasma weist eine sehr feinkernige Granulirung auf, welche sich in Eosin intensiv roth, in Triacidmischung deutlich violett färbt, während sie in der neutralen Farbmischung einen rothvioletten Ton annimmt, jedoch in letzterer oft von solcher Blässe, dass die meisten Zellen gar nicht granulirt scheinen.

52. Spärlicher Eiter von einem ulcus durum penis. Dichtgedrängt liegen eckige Kerne, so dass ihre Zusammengebörigkeit zu einzelnen Zellen nur schwer oder kaum zu erkennen ist. Das Plasma ist locker gekörnt mit grossentheils freien, doch auch in derselben Zelle liegenden, groben, ringförmigen hypeosinophilen Granulis.

53. Dünner, spärlicher Fiter von einem ulcus durum penis. Meist vierkernige Rundzellen, Kerne wie gewöhnlich abgerundet, oval, Plasma ziemlich dicht mit sehr feinen und stellenweise auch gröberen (conglobirten) hypeosinophilen Granulis gefüllt.

Im Hinblick auf die im Allgemeinen herrschende Uebereinstimmung der von den verschiedensten Schleimhäuten herstammenden mit den auf serösen Häuten ausgewanderten Zellen wird man darauf hingelenkt, ob nicht auch die Zellen des Sputum resp. der entzündlichen Schleimhaut-Producte überhaupt als Wanderzellen angesehen werden dürfen. Bestärkt kann diese Auffassung nur dadurch werden, dass, wie aus nachfolgender kleinen Untersuchungsreihe erhellt, die eigenthümlichen hypeosinophilen Granula auch in den Zellen entzïndlich neugebildeten Gewebes, wie es die polypösen. Schleimhaut-Neubildungen darstellen, sich vorfinden:

\section{Polypengewebe.}

Um die Granula vor der Färbung möglichst unbeeinflusst von chemischen und physikalischen Einwirkungen zu halten, wurde auf Schnittpräparate verzichtet. Die Geschwülstchen 
wurden durchschnitten, die Schnittfläche abgekratzt und der Saft, auf Objectträgern angetrocknet, ohne weiteres zur Färbung gebracht.

54. Schleimpolyp (ödematöses Fibrom) der Nase. Die Rundzellen führen mehrere, in Triacid sich dunkelblau färbende Kerne, ihr Plamas ist reichlich grob granulirt. Zahlreiche grobe, lichtbrechende und etwas feinere Granula finden sich auch frei im Gesichtsfelde. Diese Granula haben in Triacid einen etwas ins Blaue spielenden, dunkelrothen Farbton, in Eosin färben sie sich roth wie gewöhnlich, und sind säure- und alkalibeständig; in Neutralfarb-Mischung erscheinen sie blassroth.

55. Schleimpolyp der Nase. Der grössere Theil der Rundzellen hat einen bis zwei Kerne und ist reichlich mit lichtbrechenden, groben eosinophilen Granulis versehen. Die anderen Zellen haben meist mehr Kerne, und feine hypeosinophile, aber alkali-widerständige Granula. Im Freien liegen massenhaft eosinophile Körnchen. In Neutralfarbe sind die eosinophilen Granula blassroth.

56. Schleimpolyp der Nase. Die meisten Zellen sind mehrkernig und fein hypeosinophil gekörnt. Ausserdem einige zweikernige Zellen mit ziemlich feinen eosinophilen Granulis. Ebensolche liegen im Freien.

57. Polypoïd veränderte Schleimhaut aus einer Kieferhöhle. Während bei den letzten drei Fällen ausserordentlich wenig Zellen im ganzen Präparate waren, ist hier das Gesichtsfeld ganz gespickt mit Rundzellen. Dieselben sind meist mehrkernig und fast ausschliesslich (in Triacid) hypeosinophil fein granulirt. Ganz selten sieht man eine mehrkernige, ziemlich fein granulirte eosinophile Zelle. Färbt man mit Eosin und Methylenblau, so erscheinen die vorher roth gewesenen, feinen Granula durchweg intensiv blau, also basophil. Färbt man dagegen sofort mit Methylenblau oder Thionin, so färbt sich kein einziges Granulum. Auch vorherige Anwendung von Essigsäure ändert nichts hieran; dagegen treibt, wie gewöhnlich, Essigsäure die eosinrothe Färbung der feinen Granula aus.

Ueberblicken wir diese Untersuchungen, so springt in erster Linie die ziemlich durchgehende Gleichwerthigkeit der Zellen des Sputum (im weitesten Sinne) mit denjenigen des 
entzündeten Gewebes in die Augen. Vielleicht wäre das nicht so auffallend, wenn nicht zugleich unsere Resultate im Gegensatze zu der bisherigen Annahme stünden, wonach die Zellen des Eiters oxy- und neutrophile Granulirung aufweisen sollen. Bei den unseren war das im Allgemeinen ja nicht der Fall, ja wir haben sogar kein einziges Mal mit Ehrlich's NeutralfarbenGemisch, Berganzini's Farbenmischung oder Triacid die für Neutrophilie charakteristischen Färbungen erzielen können. Das fällt umsomehr auf, als die Feinheit der Körnung ja gerade vollkommen der sonstigen neutrophilen Granulation entsprechen würde. Warum färben sich also die feinen Körnchen nicht neutrophil? Mit Recht wird man da entgegenhalten können, das liege an unserem Verfahren oder an unseren Farben; speciell beim Triacid kann man auch noch daran denken, dass manchem Auge vielleicht die Unterscheidung des (easinophilen) rothen Farbtones von dem (neutrophilen) violetten unzugängig sei. Darauf kann man sich auch nicht verlassen: Entscheidend dafür, dass wir es mindestens nicht mit dem, was man als neutrophil zu bezeichnen noch berechtigt ist, zu thun haben können, ist die Färbbarkeit dieser feinen und feinsten Granula mit Eosin, eine Färbbarkeit, die gerade an den Zellen des Trippers den höchsten Grad leuchtender Intensität erreicht hat. Und wenn man noch ausweichen wollte mit der Annahme, dann seien eben wohl ausser den doch vorhandenen neutrophilen Granulis auch solche hypeosinophile vorhanden, so ist dem nur noch zu entgegnen: Nein, denn fast ausnahmslos besassen sämmtliche Zellen diese Färbbarkeit mit Eosin.

Es wird also in Zukunft unbedingt nöthig sein, Untersuchungen auf Neutrophilie der Entzündungs-Zellen durch eine Prüfung anf Eosin-Färbbarkeit zu ergänzen.

Ebenso ergeht es den Befunden eosinophiler Granula, speciell in Sputum, aber auch in anderen Entzündungs-Producten. Bei den meisten derjenigen Autoren, welche die Eosinophilie als dankbare Fundgrube voraussichtlich interessanter Beziehungen verarbeitet haben, finden wir keine Erwähnung der von ihnen verwendeten Methoden, aber auch keine Bemerkung über die sonstige Beschaffenheit der bemerkten Granula z. B. bezüglich Grösse oder Vertheilung, welche doch zur Bestimmung durch- 
aus nothwendig sind. Da ist es wohl nicht zu viel, zu vermuthen, dass so und so oft Granula, welche nur den Werth unserer hypeosinophilen Körnchen besassen, als eosinophlile mitgelaufen sind. Wenigstens sind von mehreren competenten Beobachtern die hypeosinophilen Granula meiner Präparate in EosinMethylenblau- und Triacid-Färbung, ohne Kenntniss des weiteren Verhaltens, sofort als eosinophil angesprochen worden. Das erklärt dann wohl auch die ungleichen Erfahrungen mancher Autoren über Eosinophilie im Sputum, wie sie oben erwähnt werden, nicht minder, wie die entschiedene Regellosigkeit im Vorkommen wirklich eosinophiler Zellen. Denn gegen die Bedeutung früherer negativer Befunde kann man man schliesslich nicht viel einwenden, da gerade die Färbung der eosinophilen Granula von vorheriger, weniger zarter Behandlung der Präparate unabhängiger ist. Und doch haben z. B. Schmidt bei eitriger, Gollasch bei fötider Bronchitis keine solche Granula gesehen, während ich bei beiden Arten solche fand. Dass ich bei Phthise zweimal eosinophile Granula, noch daza feinen Korns sah, will icb gar nicht einmal rechnen. Es lag mir auch nicht daran, an einer grossen Menge von Fällen etwaige zufällige Eosinophilie heraus zu bekommen, sondern es erschien viel werthvoller, das regelmässige Verhalten der Sputumzellen auszuforschen. Und dies liegt unzweifelhaft in der Hypeosinophilie. Wenn auch keine anderen Granula-Arten, speciell keine basophilen zur Beobachtung kamen, so stehen wir allerdings auch damit in einem gewissen scheinbaren Gegensatze zu früheren Untersuchern. Lenhartz ${ }^{7}$ und Mandybur ${ }^{8}$ hatten ja solche im asthmatischen Sputum gesehen. Mastzellen-Färbung war ausserdem von $\mathrm{Fink}^{6}$, allerdings nicht sicher, dann von $\mathrm{Schmidt}{ }^{2}$ in sehr geringer Anzahl bei gewöhnlicher und fibrinöser Bronchitis, sowie bei Pneumonie gesehen worden. Unsere Präparate zeigten nichts dergleichen. Wohl kamen mehrfach Gebilde vor, welche bei oberflächlicher Betrachtung zu Deutung in ersterem Sinne veranlassen konnten. Speciell sind es Anbäufungen von Kokken im oder auf dem Protoplasma einzelner Zellen, welche basophile Körnung (in Methylenblau) vortäuschen können; dann sahen wir auch grosse Platten-Epithelien, deren Plasma so blass gefärbt war, dass es bei etwas oberflächlicher Betrachtung ganz 
dem Blick entschwand, während der überleukocytengrosse Kern in seiner lebhaften Körnung eine Rundzelle mit Granulirung vortäuschte; endlich bildet auch die Farbe (Methylenblau oder Mastzellen-Färbung) mitunter so feinkörnige Niederschläge, so täuschend gerade an den Zellen selbst haftend (Fig. 9), dass man nur zu geneigt ist, dieselben für Einschlüsse in Plasma essentieller Natur zu halten, bis genaueste Betrachtung vieler derartiger Elemente ihre recht ungleichartige Grösse (gegenüber den im Allgemeinen doch nicht zu differenten Granulis), sowie ihre Anordnung auch ausserhalb von Zellen erkennen lässt. Von Bakterienhaufen unterscheidet man basophile Granula leicht durch Control-Färbung mit Säurefuchsin, während die ersterwähnte Kern-Granulirung (Chromatinnetz) in grossen Epithelien allerdings genaueste Aufmerksamkeit zur Unterscheidung erfordert. Aber die Nichtfärbbarkeit in Thionin genügt, um auch łetztere Gebilde in ihrer Deutung sicher zu stellen.

Auch Mastzellen-Färbung fiel bei uns immer negativ aus.

Dass dies nicht an den verwendeten Färbungen liegen konnte, zeigt der positive Ausfall der Versuche an Lymphdrüsen-Saft (s. u.). So bleibt zur Erklärung des Gegensatzes, nur die Annahme, dass die Mastzellen- und basophile Körnung in mehr zufälliger Weise vorkommen, und sicher jedenfalls nur bei sehr grossen Untersuchungs-Reihen angetroffen werden könnten. Dafür spricht ja auch der Umstand, dass bei so unendlich vielen Methylenblau-Färbungen des Sputum, wie sie bei Gelegenheit der Bacillen-Untersuchung vorgenommen werden, bisher noch nichts derartiges aufgefallen ist. Der Zufallswerth von Mastzellen-Funden erhellt aber erst recht, wenn man weiss, dass Neisser ${ }^{\tau}$ gelegentlich einmal sogar Gonorrhoë-Eiter ganz aus Mastzellen aufgebaut fand.

Im Gegensatze zu solchen wirklich nur gelegentlichen Befunden vermag die Constanz der Hypeosinophilie viel mehr unser Interesse zu fesseln. Hatten doch unter 57 daraufhin gefärbten Sputis und entzündlichen Secreten nicht weniger als 30 diesen Befund in typischer Form aufzuweisen, in weiteren fünf Fällen war dieselbe Farben-Reaction in schwächerem Grade vorhanden, (in einem ungleichmässig), bei anderen sechs vollkommen typisch, nur dass die Granula selbst etwas gröber waren, als 
gewöhnlich; und nur zehnmal war die Farb-Reaction selbst als andersartig anzusprechen. Dass bei den sechs Fällen von Cystitis und Exsudat (42-47) besondere Gründe das Nichteintreten von Färbung erklärlich machten, ist ja schon an seinem Ort auseinander gesetzt worden.

So bleiben also eigentlich dreissigmal gut und typisch gefärbte und gestaltete Granula auf 21 abweichend sich verhaltende. Das wäre allerdings eine starke Minorität, wenn nicht auch bei ihr die Hypeosinophilie immer den Grundton abgeben würde. Allerdings, die Reaction auf die in Betracht kommenden Farbstoffe ist bei dieser Minorität ungleichmässig. Aber - und das. führt uns auf einen weiteren Punkt: auch die eosinophilen Granula unserer Präparate verhalten sich erstens etwas anders, als die des Blutes, und weiter auch nicht unter einander ganz gleichmässig. Die Zusammenstellung der verschiedenen beobachteten Nuancen bringt hier Klarheit:

Unter den 51 in Betracht kommenden Fällen fanden sich vierzehnmal Zellen mit eosinophilen Granulis vor. Sie fehlten gänzlich nur bei folgenden Kategorien: Pneumonie, Conjuctivitis, Pleura- und Pericardial-Exsudaten und Gewebseiter. Daraus einen Schluss auf ihr Nichtvorkommen in diesen Secreten überhaupt zu ziehen, wäre verfehlt, da ja bei anderen Kategorien einzelne individuelle Fälle ebenfalls in genügender Zahl negativ ausfielen. Auch ist auf die Bemerkungen bezüglich basophiler und Mastzellenfärbung zu erweisen. - Fast bei allen fällt nun die gelbrothe Färbung der Granula in Triacid-Mischung auf, während im Blute diese Farbe nicht so deutlich ist; ferner färbten sich unsere Granula nicht in der Neutral-Farbenmischung; die des Blutes nehmen aber in derselben Mischung rothen Ton an; dass die Schuld nicht an der verwendeten Mischung lag, zeigt die rothe Färbung, welche dieselben Granula innerhalb des Polypengewebes erhielten (Fall 54 und 55). Die Unwirksamkeit der von Ehrlich für $\alpha$-Granula angegebenen Färbung wurde schon oben erwähnt. Wir verzichten demnach auch darauf, unsere groben Granula ohne Weiteres als Ehrlich'sche a-Granula anzusprechen; die Bezeichnug als „eosinophil" aber in rein semiotischem Sinne ist auch weiter wohl berechtigt. 
Die aufgetretenen Differenzen in der Färbung sind nun folgende:

In Fall 28 hatten die groben Granula in Triacid deutlich die typische gelbrothe Farbe angenommen. In Eosin gefärbt, vermochten sich aber gegenüber dem Einflusse der Essigsäure fast nur diejenigen Granula resistent zu erweisen, welche offenbar zerfallenden, in Auflösung begriffenen Zellen angehörten. Nur wenige solche fanden sich in noch wohl erhaltenen Zellen. Die überwiegende Mehrzahl aber war hier ausnahmsweise nicht säurebeständig, denn im Plasma jener Zellen, welche nach ihrer Gestalt und Anzahl mit den in Triacid als eosinophil erkannten identisch waren, sah man jetzt keine Granula mehr; nur eine tiefsatte Färbung durch Eosin liess erkennen, dass hier das eosinophile Chromatin gelöst, aber noch nicht ausgewaschen, lagere. Diese Mehrzahl eosinophiler Granula näherte sich also dem Typus der Hypeosinophilie durch verminderte Säurebeständigkeit.

Bei Fall 54 zeigte sich sogar eine gewisse Annäherung an die Farbe neutrophiler Granula, indem Triacid den groben Körnern einen dunkelrothen, in's blaue spielenden Ton verlieh. Die Säure-Beständigkeit der eosingefärbten Granula war intact.

Aber auch in der Form zeigte sich nicht selten eine $\mathbf{A b}$ weichung nach der Seite der bypeosinophilen Zellen hin, welche im Sinne eines möglichen Ueberganges beider Formen Beachtung verdient, um so mehr, als wir auch unter den hypeosinophilen nicht weniger als sechsmal die feine Structur der Körnchen ganz oder theilweise vermissten. Zweimal, (nehmlich Fälle 35 und 53) waren neben den gewöhnlichen feinen etwas gröbere Granula in den gleichen Zellen vorhanden, dreimal (Fälle 48, 49 und 70) waren alle sichtbaren Granula weniger fein als sonst, und einmal gar (Fall 52) fanden sich neben den gewöhnlichen feinen Körnchen ganz grobe, bei verschiedener Einstellung sogar ringförmig aussehende im Plasma der gleichen Zellen.

Nur in neun Fällen waren ferner die eosinophilen Granula grobkörnig, bei verschiedener Einstellung bald ringförmig, bald scheibenförmig erscheinend. Einmal war die Granulirung etwas feiner, viermal aber ungefähr ebenso fein, als die derhypeosinophilen. Nun vertheilt sich die Verschiedenheit der Gestalt nicht etwa 
immer nach Kategorien, denn sowohl im Nasensecret (23 und 24), als bei Gonorrhoë (38 u. 39) fanden sich grobgranulirte und fein granulirte bei nur individuell verschiedenen Fällen vor. Ein principieller durchgreifender Unterschied zwischen eosinophilen: und hypeosinophilen Granulis lässt sich also aus der Form derselben nicht ableiten. -

Ebensowenig, wie aus Farbe und Form lässt sich aber auch aus der Beschaffenheit und Zahl der Kerne und Zellen ein durchgreifender Unterschied zwischen den zwei Zellarten construiren:

Wenn wir das Vorkommen einkerniger Zellen betrachten, finden wir solche in fünf Fällen $(13,21,24,35,50)$ hypeosinophil granulirt. Eosinophile einkernige Zellen fehlen aber auch nicht: Fälle 1, 5, 8, 39 und 64. Auch das Vorkommen besonders vieler Kerne (Fälle 15 und 66) scheint bedeutungslos zu sein, denn in ersterem Fall waren nur hypeosinophile, bei letzterem auch zweifelhaft hypeosinophile (s. u.) Granula sichtbar.

Auffallend war, besonders in Triacid-Färbung, die verschiedene Tinction der Kerue, der einen hellblaugrün, der anderen dunkelblaugrau. Aber in der überwiegenden Mehrzahl der Fälle war dieser Unterschied bezüglich der Granula bedeutungslos, wie denn auch die Lymphocyten der peribronchialen Drüsen, in welchen sich gar keine Körnung vorfand, diese zwiefache Kernfärbung annahmen. Nur in vier Fällen verhielten sich die verschiedene Kerne führenden Zellen auch different bezüglich der Granulirung. Zweimal nehmlich (Fall 23 und 64) waren nur die mit hellen Kernen versehenen Zellen eosinophil, die anderen dunkleren dagegen hypeosinophil granulirt. In zwei Sputis waren nur durch Säure entfärbbare Granula, welche aber je nach den Kernen ein ähnliches Verhalten der Färbbarkeit zeigten. In den hellkernigen Zellen von Fall 66 waren deutliche hypeosinophile, in Triacid rothe Granula, in den dunkelkernigen aber spielte die Granula-Färbung mehr ins bläuliche, also in den neutrophilen Ton. Aehnlich war es mit hell- und dunkelkernigen Zellen bei Fall 68, nur war die Granulirung der letzteren in diesem Falle überhaupt sehr undeutlich, theils gar nicht bestimmbar, und Granula, welche in ihrem Farbton mehr zur Neutrophilie hinneigten, fanden sich hier in Zellen, welche zugleich helle und dunkle. Kerne führten. 
Letzteres Verhalten, zweierlei Kernfärbung durch Triacid in einer Zelle, ist übrigens in unseren Präparaten etwas ganz Gewöhnliches, und im allgemeinen ohne Belang für die GranulaFärbung gewesen (Fig. 4, h u. k).

Kerne welche, nach geltender Auffassung wenigstens, ihrer Form bezw. Färbbarkeit nach Zeichen beginnender oder fortgeschrittener Karyolyse ${ }^{12}$ aufweisen, kamen in Zellen wiederum verschiedener Granulirung vor. Fall 32 liess nehmlich in vielen Kernen Vacuolen erkennen, einzelne Kerne hatten Hufeisenform angenommen. Die (feinen) Granula blieben in Eosin recht blass und batten in Triacid einen Stich in's Violette, jedoch nicht in diesen Zellen allein, sondern auch in den anderen mit ganz normalen Kernen. Granula verschiedener Stärke, hypeosinophil gefärbt, waren bei Fall 35 sowohl in normalkernigen Zellen, als solchen mit je einem grossen Kern oder hufeisenförmigen Kernen zu finden. Endlich waren die Granula des Falles 37 auffallend blässer in jenen Zellen, deren Kerne starke Degenerations-Zeichen (Vacuolen Fig. 6) aufwiesen. Aber wir dürfen nicht übersehen, dass verschiedene Stärke hypeosinophiler Granula, und ebenso verschiedene Färbbarkeit nicht an derartig degenerirte Kerne gebunden sind; wir haben sie auch bei ganz gut gefärbten und gestalteten Kernen gefunden, und wiederum, wie im Fall 33, hufeisenförmige Kerne in Zellen mit ganz typisch hypeosinophilen Granulis. (Nebenbei sei noch auf die Aehnlichkeit der von uns beobachteten Vacuolen mit jenen hingewiesen, welche Ehrlich ${ }^{10}$ in nicht granulirten Zellen des MeersehweinchenBlutes zu $15-20$ pCt. der Gesammtzahl antraf. Bei uns waren die Zellen hypeosinophil granulirt.)

Sehen wir so keine wesentliche Abhängigkeit der Granula von der Kernbeschaffenheit, so vermissen wir solche auch weiterhin in Bezug auf die verschiedenen Lebens-Stadien des Zellplasma selbst. Zahlreich sind uns ja die Auflösungs-Vorgänge an Zellen vorgekommen, von leichter Verwischung der Conturen bis zu hochgradiger Aufquellung und totalem Zerfall mit Rücklassung nur diffuser, fetziger Massen. Aber dass eine bestimmte Farbreaction gerade dem Degenerations-Vorgange eigenthümlich sei, liess sich nicht finden. Sahen wir doch hypeosinophile Granulirung eben so gerne (Fälle 13, 14, 23, 37, 50) in solch zer- 
fallenden Zellen, als eosinophile (Fälle 24, 28 und 33) (s. a. Fig. 5). Durften wir sonach weder in Kern-, noch in Zellbeschaffenheit irgend etwas für differente Granula-Arten Charakteristisches feststellen, so drängt sich im Hinblick auf die schon erörterten Uebergangs-Formen zwischen eosino- und hypeosinophilen Granulis die Frage nach der Constanz dieser Gebilde überhaupt auf. Dieselbe wird um so brennender, wenn man das färberische Verhalten der hypeosinophilen Granula an sich durchmustert. (Es sollen hier die Befunde im Gewebe [Polypen] mit herangezogen werden.) Unter im Ganzen 61 Fällen fanden sich nehmlich 15 mal Abweichungen vom Typus der Färbbarkeit.

Eine gewisse Annäherung an Eosinophilie zeigten 3 Fälle durch Annahme von Farben, welchen die Granula sonst unzugängig blieben. Fall 29 zeigte Färbbarkeit der hypeosinophilen Granula in Ehrlich's Hämotoxylin-Eosin und $\alpha$-Farbmischung, Fälle 40 und 41 Rothfärbung derselben im Neutralgemisch. Im Gegensatz hierzu wirkte die Farbe, speciell Triacid, auf die Granula in 5 Fällen $(26,67,68,74,76)$ weniger ein, so dass die Färbung theils blasser, theils sogar unbestimmbar ausfiel.

Eine gewisse Annäherung an neutrophile Reaction zeigten die Granula der Fälle 32, 65 und 66. Bei ersterem wurden sie in Eosin nur sehr blass gefärbt und erhielten im Triacid einen Stich in's Violette; Fall 66 zeigte in Triacid eine Verfärbung der Granula dunkelkerniger Zellen in's Bläuliche, und bei 65 färbten sie sich sogar in für Neutrophilie charakteristischer Weise violett. Aber immer noch fehlte ihnen die Färbung im Neutralgemisch.

Auch diese konnte aber bei den Granulis des Falles 51 gefunden werden, welche auch in Triacid durch rothvioletten Ton eine gewisse Neutrophilie verriethen. Allerdings blieb die Färbung in Neutralmischung immer noch so blass entwickelt, ja fiel sogar häufiger ganz aus, dass ein sicheres Ansprechen für eine bestimmte Reaction ausgeschlossen war.

Auch waren die Granula dieses, wie der vorhergehenden drei Fälle immer noch in Eosin, theilweise sogar sehr gut färbbar. Ganz gelockert wurde der Zusammenhang der Granula-Reaction mit der Eosinophilie nur im Falle 64, wo Eosin die im Triacid rothvioletten Körnchen ganz ungefärbt liess. Trat somit in diesen 
Fällen und besonders bei 51 eine getheilte Vorliebe der Körnchen für saure und neutrale Farbstoffe zu Tage, so war noch das Merkwürdigste dem Falle 57 vorbehalten, dessen Granula in gleich intensiver Weise sauren and basischen Farbstoff wählten. Zwar hatten wir schon beim Sputum bemerkt, wie das Methylenblau das Eosin sozusagen auszutreiben suchte, indem bei längerer Einwirkung die Granula einen bläulichen Ton annahmen; hier aber verschwand in der That die Eosinfärbung gänzlich, um einer unzweifelhaft basophilen Platz zu machen. Dabei ist die Resistenz vorher ungefärbter Granula gegen basische Farbstoffe noch besonders beachtenswerth, denn weder mit Methylenblau, noch Thionin liessen sich ohne vorherige Eosinfärbung Granula darstellen.

Dieses Verhalten, sowie dasjenige im Fall 51 und 64, muss demnach als eine $A m p h o p h i l i e$ angesprochen werden, allerdings. nicht in dem Sinne, dass sich, wie bei H. F. Müller ${ }^{13}$, in ein und derselben Zelle des Knochenmarkes feine rothe und gröbere violette Granula in Neutralfärbung darstellten, sondern so, dass Granula unter Umständen auf zweierlei Farben Anziehungskraft auszuüben vermögen. - Sucht man die Fälle verschiedenartigen Verhaltens an unseren Zellen im Zusammenhange zu überblicken, so zeigen sich folgende Eigenthümlichkeiten und Varietäten, zunächst der Granula:

1. Eosinophile, grobkörnige, säurewiderständige Granula mit in Triacid deutlicher (gelbrother) Farbreaction und Nichtfürbbarkeit in Ehrlich's $a$-Färbung und Neutralfarb-Mischung.

2. Ebensolche Granula, aber in Neutralfarbe roth tingirt.

3. Ebensolche, aber durch Säure auflösbare Granula.

4. Eosinophile, feinkörnige Granula.

5. Hypeosinophile, feinkörnige Granula, gekennzeichnet durch Entfärbung des Eosin nur durch Säure.

6. Ebensolche, auch durch Alkalien entfärbbar.

7. Ebensolche, durch Neutralfarbe roth darstellbar.

8. Ebensolche, in Triacid und Eosin nur schwach roth färbbar.

9. Ebensolche mit Triacid-Färbung, welche an Neutrophilie erinnert, neben deutlicher Eosin-Färbbarkeit.

10. Ebensolche mit deutlicher neutrophiler Färbung neben deutlicher Färbung in Eosin. 
11. Ebensolche mit ausgesprochener Färbbarkeit sowohl in Eosin, als Methylenblau.

Es ist das eine ziemlich geschlossene Reihe von Uebergängen einer Farbreaction in die andere. Aehnliches hat $\mathrm{Ehrlich}^{10}$ bereits an Zellen des Knochenmarkes, speciell bei Meerschweinchen constatiren können, indem während der Umbildung der uninucleären Zellen zu den multinucleären auch die Beschaffenheit der Körnelung sich ändert". Die jungen, einkernigen Zellen des Meerschweinchens mit jener pseudo-eosinophilen Körnung, auf deren Aehnlichkeit mit unserer hypeosinophilen bereits oben verwiesen wurde, färbten sich nehmlich "nach länger dauernder Fixirung in überhitztem Wasserdampf in Eosin-Methylenblau bläulichroth“. In den multinucleären Zellen fand sich dagegen nur Rothfärbung derselben Granula. Einen derartigen Unterschied bemerkte man ja in unseren Präparaten auch, doch nicht auf ein- und mehrkernige Zellen vertheilt. Vielleicht liegt das an der Erhitzung bei Ehrlich, jedenfalls aber war bei uns stärkere Blaufärbung der eosingefärbten Granula und, unabhängig von der Zellform, bei verschiedenen Individuen zu bemerken.

$\mathrm{Ob}$ überhaupt das Alter der Zellen von wesentlichem Einfluss auf die färberische Beschaffenheit der Granula ist, das wenigstens für unsere Objecte zu entscheiden, fällt um so schwerer, als wir gerade bei alten und ältesten, nehmlich im Zerfall begriffenen Zellen ebensowohl eosinophile, als hypeosinophile Tinction angetroffen haben. -

Eine andere Variabilität innerhalb der eosinophilen Gruppe besteht in den Zellformen selbst, wie schon Ehrlich ${ }^{14}$ und Müller ${ }^{12}$ für das Rückenmark es beschrieben haben, bezüglich Grösse, Gestalt und Kernfigur. Auch an unseren Zellen fehlte diese Verschiedenheit bei sonst gleichem Verhalten der Granula nicht.

Wichtiger erschien aber der Uebergang von Eosinophilie zu Hypeosinophilie und von da zu Neutrophilie, ebenso der von Derbkörnigkeit zu Feinkörnigkeit, wie er aus unseren Untersuchungen erhellt. Grob- und feinkörnige Granula in ein and derselben Zelle, und beide eosinophil, sind zwar schon von Schaffer ${ }^{14}$ in der an eosinophilen Zellen reichen Thymus gefunden worden, auch Müller ${ }^{13}$ bildet solche vom Knochenmark ab, für uns aber ist vor allem das Vorkommen nur feinkörniger, 
dabei aber eosinophiler Granula in allen Zellen desselben Präparates bedeutungsvoll, weil damit auch morphologisch eine Zwischenstufe der scheinbar so getrennten Granula-Kategorien hergestellt wird.

Man kann, ja man muss sich wohl vorstellen, wie all' diese Granula nichts principiell Verschiedenes sind, sondern unter uns noch unbekannten Einflüissen Umwandelungen erleiden können. Man hat den bestimmten Eindruck, auch bei den eosinophilen Körnchen, nicht constanten Grössen, sondern einer labilen Masse gegenüber zu stehen, und wird um so mehr Schlüssen, welche aus dem zufällig hier mehr, dort minđer häufigen Antreffen einer bestimmten Form gezogen werden wollen, mit höchstem Misstrauen begegnen. Eine Scheidung der verschieden granulirten Zellen auch nach ihrer äusseren Form konnten wir ja nur ein einziges Mal (Fall 28) beobachten; aus einem so vereinzelten Befund lassen sich aber kaum Deductionen ableiten. Wohl aber ist im Hinblick auf die Variations-Möglichkeit der Umstand sehr wichtig, dass (v. Noorden ${ }^{15}$ u. A.) beim Asthma eosinophile Zellen nur zeitweise, nur nach Anfällen in grösserer Zahl angetroffen werden. Welche Bedeutung dabei der Vermehrung eosinophiler Zellen im Blute sowohl bei dieser Krankheit, als bei manchen anderen (Rieder ${ }^{16}$, Müller $^{17}$, Klein ${ }^{18}$, Ehrlich ${ }^{10}$ ) zukommt, das hier zu erörtern kann um so mehr unterbleiben, als dem Zwecke vorliegender Arbeit mehr die Sicherstellung von Thatsachen, als die Aufstellung von Hypothesen entspricht.

Es ist nun noch auf die im allgemeinen geltende Identität der Zellen entzündlicher Producte und entzündlich entstandenen Gewebes zurückzukommen, schon um die Frage nach der Herkunft der ausgeschiedenen Zellen beantworten zu können. Denn wenn diese und diejenigen im Gewebe stark übereinstimmen, könnte man eher an gleiche Abstammung denken. Nun sind wohl in dem Gewebe der Polypen auch Verschiedenheiten gegenüber den Secretionszellen vorhanden gewesen; als durchgehender Befund kehrt aber auch bei jenen immer die Hypeosinophilie wieder. Das giebt uns aber noch keinen Aufschluss, ob die Zellen aus dem Blut oder dem Gewebe stammen. Nach Neumann's ${ }^{19}$ und Ehrlich's ${ }^{10}$ Angaben wäre dies leicht zu entscheiden, da frisch erzeugter Eiter, bezw. frische Entzündungs- 
heerde nur multinucleäre Elemente enthalten. Da aber in unseren Präparaten einerseits einkernige Zellen vorkommen, anderseits solche auch im ,späteren Verlauf der Entzündung " nach Ehrlich anzutreffen sind, ist hier auch keine Lösung enthalten. Es ist auf den ersten Blick sogar nicht wahrscheinlich, dass diese Zellen aus dem Blute stammen. Denn einmal sind die multinucleären Zellen des. Blutes neutrophil ${ }^{1}$ ), und dann sind vach Ehrlich gerade die granulirten Zellen des Blutes diejenigen, welche zur Auswanderung bestimmt sind. Die Hypeosinophilie liesse also vielmehr an eine Entstehung der Zellen aus den sich theilenden Gewebszellen denken, weil ja im Blut bisher ${ }^{1}$ ) keine Hypeosinophilie beobachtet worden ist. Aber das ist ein schwacher Grund, da die Granula ja auch im Gewebe bisher noch nicht bekannt waren. Auch könnte man sich wohl vorstellen, dass bei der unzweifelhaften Nahe- und Zwitterstellung der hypeosinophilen za den eosinophilen und neutrophilen Zellen erst während gewisser Processe eine Umwandlung dieser in jene erfolgte. Wir können also die Frage ruhig mit derjenigen nach der Herkunft der eosinophilen Zellen in Polypen, Pemphigusblasen u. s. w. identificiren, und auf die ausführlichen Betrachtungen Ehrlich's hierüber verweisen, wonach eine Auslese dieser Zellen aus dem Blute auf chemotactischem Wege am wahrscheinlichsten sich darstellt. -

Die Frage nach der Entstehung zieht auch gleich die nach dem weiteren Ergehen der Granula nach sich. Wir sahen ja ausser den intracellulären überall meistens massenhafte Grauula in dem schleimigen Stratum der Sputa u. s. w. verstreut. $W_{0}$ kommen diese her? Im Stratum selbst werden sie wohl kaum entstanden siin, um dann nach Phagocyten-Art von den Zellen aufgenommen zu werden; dagegen spricht ibre ebenso häufige Anwesenheit im Serum des Gewebs-Eiters und ihre regelmässige Anhäufung um Kerne in Auflösung begriffener Zellen: Bereits vernichtete Zellen können nicht mehr fressen. Sonach sind sie jm Zellkörper selbst enthalten und verlassen denselben erst, um frei verstreut zu erscheinen. Das aber geschieht sicher nicht durch Zerfall der Zellen, denn die geringe Anzahl sich auflösender Zellen steht in zu unvereinbarem Contraste mit der Anzahl freier

1) S. dagegen Grünwald, Centralbl. f. innere Medicin. 1899. No. 30. 
Granula. So muss man wohl an eine Art ständiger Absonderang der Körnchen aus dem Zellkörper heraus denken, nach Analogie etwa eines Excretions-Vorganges. Damit würde auch übereinstimmen, dass eine Vermehrung der secernirten eosinophilen Zellen im allgemeinen Hand in Hand geht mit einer gleichen Vermehrung im Blute, welche nach Müller ${ }^{17}$ "stets auf chronische Veränderungen der blutbereitenden Organe" hindeutet.

Diese Ausscheidung aus den Zellen nach aussen konnte ja. auch Hankin ${ }^{20}$ durch Abnahme der Granula nach Verweilen der Blutproben im Thermostaten, und Janowski ${ }^{21}$ direct an stagnirendem Eiter nachweisen. Die neutrophilen Körner verschwinden hier sogar gänzlich.

(Wir durften sonach auch bei Fall 19 getrost die nicht granulirten Zellen den anderen als gleichwerthig ansehen, da ja auch auffallend dürftig granulirte sich im selben Präparate fanden.)

In der Auffassung der Granula als Stoffwechsel-Producte ergiebt sich also für die Zellen des Sputum u. s. w. keine Abweichung von der durch Ehrlich bereits für die Blutzellen aufgestellten 'Theorie.

Fragen wir endlich nach der biologischen Bedeutung der Granula in den entzündlichen Secreten, so können wir einzelnen Formen derselben bei der uns jetzt bekannten Variabilität keine zu hohe Bedeutung beimessen. Die Zeiten sind ja wohl ohnedies vorüber, wo z. B. Neusser ${ }^{22}$ sich durch einseitige EosinophilieFunde soweit begeistern lassen konnte, dass er unter vollem Beifall von St. Klein ${ }^{18}$, vor dem Vorschlage der Castration bei sehweren und unheilbaren Hautleiden (!) nicht zurückschreckte, da vermehrte Eosinophilie des Blutes sowohl bei diesen, als bei Osteomalacie gefunden wurde. $\mathrm{Da}$ nun letztere Erkránkung durch Castration (!) behandelt wurde, war die logische Brücke zur gleichen Behandlung jener Leiden auf dem Räcken der Eosinophilie sofort geschlagen.

Das geht denn doch zu weit. Viel sympathischer ist uns Müller's ${ }^{17}$ Anffassung, wonach "den eosinophilen Zellen eine durch nichts berechtigte Sonderstellung unter den übrigen leakocytären Zellen" verliehen worden ist. - 
Als schliessliches Ergebniss unserer Untersuchung bleiben somit folgende Punkte:

Erstlich die im Grossen und Ganzen herrschende Uebereinstimmung zwischen den Zellen des Sputum, anderer entzündlicher Absonderungen und in entzündlich entstandenem Gewebe.

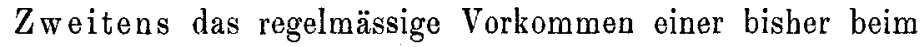
Menschen nicht bekannten Form von Granula in diesen selben Producten.

Drittens die Constatirung der ausserordentlichen Labilität im Verhalten dieser Granula. -

\section{Fremdkörperzellen.}

Das menschliche Sputum enthält zwei Arten von Fremdkörper-Zellen. Die einen führen von aussen eingedrungene Bestandtheile der Athemluft, Staub, Russ, Steintheilchen und dergl., die anderen Schlacken des Organismus selbst, nehmlich Zerstörungs-Producte von rothen Blutkörperchen mit sich. Da letzteres hauptsächlich bei der in Folge von Herzfehlern auftretenden rothen Induration der Lunge vorkommt, hat man diese Zellen kurzweg als "Herzfehler-Zellen" bezeichnet. Dieser Ausdruck greift bereits anderweitiger Deutung ihrer Entstehung ${ }^{1}$ ) vor, und so beschränken wir uns in Nachfolgendem auf den Ausdruck: Blutpigment-Zellen. (Die Natur des Pigmentes nachzuweisen, wurde immer die bisher übliche Methode der Constatirung von Eisen mittelst schwefelsauren Ammoniums, lieber noch Ferrocyankalium-Salzsäure, verwendet.)

Es ist zugleich zu betonen, dass auch Staubzellen Eisenreaction geben können, wenn und weil der aspirirte Staub eben, wie bei Metallarbeitern und dergl., Eisen enthält. Aber dieses ektogene Pigment stört uns nicht, auch solche Zellen nur als Staubzellen zu bezeichnen, da die Zellen mit endogenem (oder hämatogenem) Blutpigment besonderer Untersuchung über ihre Herkunft bedürfen, sich auch im Sputum selbst durch Gruppirung und besondere Anhäufung bei Krankheiten, welche Blut in die Luftwege befördern (Herzerkrankungen, Infarct, Pneumonie), differenziren. Die erstere Sorte von Zellen bezeichnen wir, wie

1) Bei Infarct, Asthma (v. Norden ${ }^{15}$ ), Emphysem (Wirsing ${ }^{23}$ ), Pneumonie. 
schon mehrfach oben geschehen, ais Staubzellen. Dieselben haben wir im Wesentlichen deswegen untersucht, um zur Aufklärung der Herkunft der Blutpigment-Zellen beizutragen. Man hat sich ja nach und nach so ziemlich geeinigt, letztere als AlveolarEpithelien anzusehen, und mangels lauterer oder begründeter Widersprüche in letzter Zeit sogar den Beweis hierfür nicht mehr benöthigt. Es war unsere Aufgabe, aus der Literatur und am Object die Begründung dieser Auffassung za controliren.

Finden sich diese pigmentirten Zellen in den Alveolen? Ist Pigment im Alveolar-Epithel vorhanden? - Sucht man in der ersten anatomischen Arbeit über das Lungen-Pigment, in der Zenker'schen ${ }^{24}$ ), nach Aufschluss hierüber, so erfährt man nur Negatives, um so begreiflicher, als Zenker ja überhaupt die Existenz eines Alveolar-Epithels leugnete. Er fand auch kein Pigment in den Flimmer-Epithelien der Bronchi. Die Staubkörnchen sollen dagegen in die platten Epithelien der Endverzweigungen eindringen, welche sodann sich vergrössern und kugelig werden, und durch Aspiration sich in den Alveolis anhäufen. Diese Metamorphose kleiner, platter Zellen in grosse, kugelige hat man auch in neueren Arbeiten wieder hervorgeholt, um den merkwürdigen Gegensatz zwischen den verhältnissmässig kleinen Zellen, welche man als Alveolar-Epithel anspricht, und den meistens grossen Gebilden, welche im Sputum das Pigment enthalten, zu überbrücken. Es wäre vielleicht werthvoller gewesen, anstatt durch diese Hypothese die Möglichkeit darzuthun, dass die Pigment-Zellen Alveolar-Epithel seien, lieber die Thatsächlichkeit der Existenz von Pigment im Alveolar-Epithel dort, wo man es sicher als solches ansprechen kann, wehmlich in situ, zu beweisen. Zwar hat Tschistovitsch bei Thieren experimentell dies bereits versucht, und ist dabei zu Resultaten gekommen, welche für die Lehre vom Alveolar-Epithel eigentlich vernichtend sind. Er fand bei Meerschweinchen, denen er Lampenruss einzuathmen gab, nie Pigment in den Epithelien, und bei Kaninchen zeigte sich die leukocytäre Natur grosser, epithelähnlicher Zellen, welche intratracheal eingespritzte Streptokokken wieder nach aussen führten, sehr deutlich dadurch, dass sie zugleich Carmin, welches er intravenös injicirt hatte, enthielten. Aber beim Menschen 
und für natürliche, nicht experimentelle Verhältnisse, konnte man einwerfen, war das noch nicht beweisend.

Ich habe nun Schnitte einer Anzahl Lungen daraufhin untersucht. Es waren theils Lungen mit dem gewöhnlichen Staubpigment der Culturmenschen, theils ausserordentlich stark pigmentirte von einem Kaminkehrer, endlich Lungen mit brauner Induration. Es wurde für pöthig erachtet, sich ausser dem $\mathrm{Be}$ satze der Alveolen auch mit dem Bronchial-Epithel zu beschäftigen. Denn a priori lässt sich nur unter der Einwirkung bereits vorgefasster Meinung nicht einsehen, warum die Pigment-Zellen nicht auch hier ihren Ursprung haben können. Mindestens wird ein hier negativer Befund auch bezüglich des Alveolar-Epithels Misstranen erwecken müssen. Denn warum soll gerade dies Epithel vor allen anderen Epithelien bevorzugt sein?

Nun ist es gar nicht leicht, in Schnitten herauszufinden, ob und in was für einer Art Zellen sich Pigment findet, da dasselbe meist auch ausserhalb lagert und dadurch die Grenzen verwischt werden. So gelang es mir auch nur in einer nicht besonders pigmentirten Lunge, an einigen Stellen rundliche Zellen von etwa doppelter Leukocytengrösse mit 1 und 2 Kernen in 2- und 3 facher Schicht der Alveolar-Innenfläche aufgelagert zu sehen, von denen einige deutlich Staubpigment enthielten. Aber ob das wirklich Alveolar-Epithelien, ob es nicht durch die Wand getretene epithelioide Wanderzellen waren, das muss, im Hinblick auf Tschistovitsch's mit Sicherheit als epithelioide Rundzellen erkannte Pigment-Zellen, doppelt zweifelhaft erscheinen, da nur Pigment in einfach der Wand fest aufgelagerten Zellen beweiskräftig sein kann. In der ganz schwarzen Lunge eines Kaminkehrers gar konnte nichts dergleichen gefunden werden (auch das Bronchial-Epithel war ganz pigmentfrei), und um so mehr fiel es auf, dass pigmentirte Zellen, welche ganz genau den später bezüglich ihrer Eigenart näher za erörternden Staubzellen glichen, innerhalb eines Bronchial-Lumens in Schleim eingebettet lagen.

Mit den Blutpigment-Zellen verhielt es sich noch anders. Solche, wiederum in ihrem Aussehen den Herzfehler-Zellen gleich, sah ich mitten in den dichtgedrängten rothen Blutkörperchen bei frischem, hämorrhagischen Infarct, ebenso bei rother Induration. 
Es ist schwer, sich vorzustellen, dass Alveolar-Epithelien erst das Pigment aufgenommen, sich dann losgelöst und hierauf mübsam durch die breiten Schichten der Erythrocyten hindurchgearbeitet hätten. Wenn man aber an Wanderzellen der Blut-Leukocyten denkt, die, mitten im Haufen der sich auflösenden Blutkörperchen deren Farbstoff aufnehmen, das gäbe kein unannehmbares Bild. - Aber, wie man sieht, auch die Befunde an der Lunge selbst ergeben noch keinen stringenten Beweis: Angenommen, man hielte an der Identität der in den Alveolen liegenden epithelioiden Pigment-Zellen mit Alveolar-Epithelien fest, so fragt es sich immer noch, ob denn diese die einzige Quelle für die betreffenden Sputum-Bestandtheile sind. Hält man aber die Natur der intrapulmonal gefundenen Zellen für mindestens controvers, so drängt sich erst recht die Frage auf, ob denn nicht die pigmentirten Epithelien auch anderwärts entstehen und dem Sputum beigemengt werden können.

Neumann hat bereits darauf hingewiesen, dass auch im „Rachen-Sputum“ Staubzellen vorkommen. Bizzozero erhebt dagegen den allerdings recht sophistischen Einwand, dass man daraus nur folgern könne, dass selbst leichte Katarrhe der oberen Luftwege sich ohne Schwierigkeiten bis zu den Lungen fortpflanzen. So lange der Auswurf durch Husten bezw. Räuspern entleert wird, kann man dem hier enthaltenen Einwand des Herstammens aus der Lunge allerdings nicht vollständig ausweichen. Aber es geht nicht wohl an, denselben auch aufrecht zu erhalten gegenüber jenem Sputum, welches, wie bei manchen Leuten, durch heftiges Aspiriren aus der Nase oder dem NasenrachenRaum nach hinten gezogen, und dann einfach ohne ExspirationsBewegungen ausgespuckt wird. Ich habe solche Sputa unter meinen Augen produciren lassen und Folgendes gefunden:

\section{Nasenrachenauswurf.}

58. Spärlicher weiss-schaumiger Auswurf mit opaken weissen Fetzchen. Diese bestehen grossentheils aus mittelgrossen polygonalen Epithelien und einigen erheblich kleineren, ovalen, schwarz pigmentirten Zellen mit 1-2 wandständigen Kernen und netzförmig durchbrochenem Plasma; im übrigen Rundzellen.

59. Weissliches, speichelähnliches Sputum, kaum etwas 
grau. Derselbe Befund, nur dass auch kleinere Pigmentzellen sonst gleicher Beschaffenheit vorhanden sind.

60. Zähglasiges, grauweisses Klümpchen mit grauen Streifen. Enthält massenhaft sehr grosse, ovale Zellen, von denen ein Theil mit Myelintropfen, die meisten mit braunem und schwarzem, feinkörnigem Pigment gefüllt sind. Die Kerne stehen an der Wand der Zellen.

Sollte hier immer noch ein, wir dürfen wohl sagen unbe-

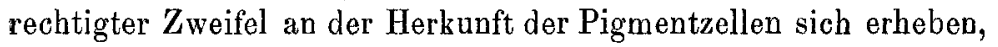
so muss dieser wohl gegenüber einem Secret schweigen, dessen Abstammung aus der $\mathrm{N}$ ase dadurch sichergestellt war, dass es nur durch Ausschneuzen erlangt wurde. Es wurde also eine Reihe von Personen, und zwar mit Vorliebe solche untersucht, welche eine stark verstaubte Luft eingeathmet hatten, wie Schlosser u. dgl. Leider fielen fast alle Befunde negativ aus. Auch in den schmutzigsten Nasenanswürfen war nehmlich das massenhaft in grossen Schollen, seltener in kleinen Körnern vorkommende Pigment niemals innerhalb irgend welcher Zellen eingeschlossen. Es ist das erklärlich, wenn man die prophylaktische, staubfangende Fähigkeit des Nasensecretes in Betracht zieht, welches die Fremdkörper offenbar nur zu kurze Zeit aufgenommen hat, um sie in Zellen verarbeiten zu können. Und so wäre gerade die hauptsächlichste Stütze für unsere Ansicht, dass nicht gerade nur die Lungen die Pigmentzellen liefern müssen, gefallen, wenn nicht zum Glück noch das Secret eines acuten Schnupfens (s. o. Fall 25) eine Menge typischer Staubzellen aufgewiesen hätte. Warum sie gerade da zu finden waren, sonst gar nicht, darüber wollen wir keine Hypothesen aufbauen, genug an dem Resultat: Das Vorkommen von Staubzellen ist nicht an das Alveolar-Epithel gebunden. - Ist es denn überhaupt an Epithel gebunden? Können nicht Zellen bindegewebiger Herkunft geradeso zu Pigmentträgern werden? Für Meerschweinchen und Kaninchen haben das die oben angeführten Versuche Tschistovitsch's zweifellos erwiesen. Dieselben stehen allerdings im Gegensatze zu älteren Versuchen Knauff's ${ }^{25}$ und Panizza's ${ }^{1}$. Aber diese können wir nicht als beweisend betrachten.

Knauff hatte Flachschnitte durch die Bronchial-Schleimhaut 


\section{6}

frisch getödteter Hunde geführt, welche vorher Russ eingeathmet hatten. Dabei sah er dann den Russ in den Becherzellen angehäuft. Panizza sah an den Becherzellen abgeschnittener. Froschmund-Schleimhaut kleine Kugeln austreten, welche (auf dem gewärmten Objecttisch) sich mit aufgestreuten Russ anfüllten. Ebenso sah er solchen von „Myelin-, Schleim-, Eiter- und Pflasterzellen" eines pigmentlosen Rachensputum aufgenommen werden.

Eigene Untersuchungen haben mich belehrt, dass es an getrockneten Präparaten meist ausserordentlich schwer, an frischen geradezu unmöglich ist, zu sagen, ob Staubkörner u. dgl. innerhalb oder ausserhalb von Zellen liegen, wenn man nicht gerade ausschliesslich im Umkreis der Zelle und conform deren sonstiger Gestalt die Fremdkörper angehäuft sieht. Da auf diese Fehlerquelle bei Knauff und Panizza nicht ausdrücklich hingewiesen ist, können wir sie nicht als ausgeschlossen betrachten.

Beim Menschen musste (trotz Tschistovitch's Resultaten) die Sache neu untersucht werden. Das geschah nun auch auf dem nicht unrationellen Wege, Eigenthümlichken, die die Epithelien gar nicht besitzen, in den Zellen aufuusuchen: Schlüter hatte bei (Lenhartz') durch Färbungen mit Ehrlich'schen Granulafarben an Schnitten und Sputum Aufschluss zu erhalten versucht, in der Voraussetzung, die Zellen würden, wenn der Leukocytenreihe angehörig, neutrophile Körnung aufweisen. „Sehr instructiv waren die Bilder keineswegs", wie Lenhartz zugestehen muss.

Vorher hatte auch schon v. Noorden ${ }^{15}$ an EisenpigmentZellen eines Falles von Asthma diesen Nachweis versucht und in der Hälfte der Zellen neutrophile Körnung, bei einigen anderen eosinophile gefunden. Damit wäre ja, besonders wenn man mit v. Noorden über die anderen nicht granulirten Zellen einfach aburtheilt: sie waren, da nichts für ihre Natur als Lymphocyten sprach, Epithelien, die Sache erledigt. Leider sind diese Befunde nicht ganz einwandfrei. Erstens hatte sich nur in ganz wenigen Zellen überhaupt eine Färbung erhalten, da sie nachher zur Färbung des Eisenpigmentes mit Ferrocyankalium-Salzsäure behandelt waren; dann ist sehr aufalllig, dass weitere Färbungsversuche an einer Spirale misslangen, „da nach Ein- 
wirkung der Salzsäure die Ehrlich'sche Färbung stets versagt". Nach meinen Erfahrungen versagt sie aber nicht blos nach Einwirknng von Säuren, sondern auch bei nachheriger Einwirkung derselben. Endlich gelang die Conservirung der gefärbten Körnchen nicht, da dieselben bald bis zum Verschwinden verblassten. Für beweisend können wir also diese Befunde nicht ansehen, bestenfalls nur für Zufalls-Ergebniss, da unsere eigenen zahlreichen Granulafärbungen gerade an Pigmentzellen, mit und ohne Salzsäure, vergeblich blieben. - Es war nöthig, einen anderen Weg einzuschlagen. Es wurde ein Organ untersucht, welches Pigment von aussen her aufnimmt, dessen Zellen aber auf Epithel auch nicht einmal verdächtig sind: das sind die peribronchialen Lymphdrüsen. Es wurden also Schnitte von solchen angefertigt; doch ohne Ergebniss. Man konnte nirgends mit Sicherheit erkennen, ob das massenhaft angehäufte Pigment auch wirklich intracellulär lag. Die Zellen mussten also isolirt werden. Das versuchte ich dadurch, dass von Schnitten der Saft abgestreift und auf Objectträgern angetrocknet wurde. Doch auch dann noch überdeckte die Kohle die Contouren, und nur durch Auswaschung des Saftes mit physiologischer KochsalzLösung gelang es endlich, klare Bilder zu erhalten.

Pigmentirte Lymphdrüsen.

61. Zwischen den stark kerngefärbten Lymphocyten liegen zablreiche $1 \frac{1}{2}-2$ Mal so grosse, stark pigmentirte Zellen mit 1-2 wandständigen blassen Kernen und durchbrochenem Plasma. Hie und da wurde eine Zelle mit normal grossem, centralem Kern, aber etwas grösserem Plasmaleib, der vollständig aus feinen, in Methylenblau stark, im Thionin blass, in beiden homochrom sich färbenden Granulis aufgebaut ist.

62. Bietet ziemlich das gleiche Bild. Nur sind die basophil granulirten Zellen zahlreicher, ihr Plasma etwas, grösser, der Kern excentrisch, bzw. ganz wandständig, und die Körnung vielleicht etwas gröber.

63. Hier fehlen Pigmentzellen gänzlich. Das sehr reiche Pigment ist in gleichmässig grossen Körnchen diffus verstreut. Ungefähr in dem Verhältniss, wie sonst Pigmentzellen, sieht man Zellen mit etwas grösseren blassen, theilweise excentrischen Kernen, deren Plasma zwar theilweise stark gefärbt, doch von 
zahlreichen Lücken durchbrochen ist, so dass die ganze Zelle, grösseren Umfang vorausgesetzt, den Staubzellen recht ähnlich sehen würde. Einige wenige Lymphocyten zeigen in EosinMethylenblau überaus feine rothe Granula. Hie und da eine grössere Zelle mit excentrischem Kern und sehr starker, gut färbbarer basophiler, nur mässig feiner Körnung. -

Es erhellt hieraus, dass Pigmentzellen typischer Art nicht des Epithels zur Grundlage bed ürfen, sondern sicher aus Lymphocyten entstehen können.

Müsser sie dies aber auch, oder können nicht doch auch Epithelien wenigsten theilweise die Pigmentzellen bilden?

Die Betrachtung der Zellen im Sputum selbst vermag uns da vielleicht Aufschluss zu geben:

Staub-und Rauch-Sputa.

64. Grünschwarz gekörnte, sonst glasige, rundliche, kleine Ballen. Zahlreiche einzelne und gruppirte Staubzellen von doppelter bis fünffacher Leakocyten-Grösse, mit ziemlich feinem, schwarzem Pigment locker gefüllt, 1-5wandständigen Kernen. Das Plasma, besonders in Eosinfärbung, fein netzartig gezeichnet, zeigt keine Granula, während die zahlreichen Rundzellen durchwegs granulirte sind und, zwar erscheinen diese mässig feinen Granula in Triacidfärbung meistens rothviolett, und zwar in Zellen, deren Kerne dunkel tingirt bleiben; eine andere kleine Partie, vorwiegend mit helleren, grünblauen Kernen (einkernig) ist deutlich roth granulirt, einzelne einkernige und ebenfalls hellkernfarbige Zellen sind deutlich gelbroth grobgranulirt, also eosinophil. In Eosin färben sich nur letztere roth, alles andere bleibt ungranuiirt. - Hie und da einige grosse Platten-Epithelien mit neutralem Kern, von Pigment nur überlàgert.

65. Grauschwarze, glasige Ballen. Dieselben bestehen meist aus dichtpigmentirten, runden bis ovalen Zellen von Leukocytenbis zu dreifacher Grösse, mit je einem randständigen Kern, feingenetztem, nicht granulirtem Plasma. In zahlreichen Zellen sieht man nach Methylenblau - Färbung blaue Körner von ungleicher Grösse, auch etwas ungleichmässigen Contouren (Fig. 9). Man wäre versucht, dieselben für Granula ( $\delta$ ) anzusehen, wenn nicht die Körnung gar zu ungleichmässig wäre. Auch ist mit Thionin nichts Derartiges nachzuweisen. Die Gewebszellen sind 
meist etwas langgestreckt, undeutlich contourirt, mit (in Triacid) dunklen Kernen und violetter, mässig feiner Körnung. Seltener runde, ein- bis zweikernige Zellen mit hellgrünblauen Kernen und rother Granulirung. In neutraler Farbmischung lässt sich keine Granulirung erkennen.

66. Spärliche, grau gestrichelte, glasige Ballen. Ganz. wenige, ovale, mittelgrosse Rundzellen mit je einem wandständigen Kern. Die zahlreichen Rundzellen sind fein hypeosinophil gekörnt. Sie'führen 2-8 Kerne, welche in Triacid bald hellblaugrün, bald dunkelblaugrau gefärbt werden. Die Granula-Färbung bei letzteren Zellen ist viel undeutlicher und spielt mitunter ins Bläuliche. Nicht selten sieht man Kern-Degenerationen nach Art der bei Fall 37 beschriebenen.

67. Sehr zähe, orangegelbe Schleimballen. Die sehr zahlreichen Staubzellen führen gelbes und braunes, feinkörniges Pigment, sind theilweise nicht viel grösser als Leukocyten, theilweise bis zu fünffacher Grösse. Sie haben meist einen wandständigen Kern und feingenetztes Plasma. Rundzellen sind ausserordentlich wenig vorhanden, ihre Körnung ist im Allgemeinen zu undeutlich, um sicher differencirt werden zu können, nur eine oder zwei hypeosinophil fein gekörnte Zellen lassen. sich klar erkennen. Weniges polygonales, pigmentfreies PlattenEpithel.

68. Glasiges, kaum etwas graues, spärliches Sputum. Sehr. viele Staubzellen, angefüllt und überlagert mit Myelintröpfchen, deren auch sehr viele freischwimmen. Auch grosse, nicht pigmentirte, stark myelinhaltige Zellen, doch ohne Pigment sind reichlich vorhanden, ebenso kleinere, kaum etwas mehr denn leukocytengrosse Zellen mit wenig Pigment gefüllt. Die pigmentirten Zellen haben ein bis drei theils wandständige, theils nur excentrische Kerne, ibr Plasma ist netzartig durchbrochen und blass. Von den Rundzellen sind alle, welche in Triacid hellgrünblaue Kerne haben, hypeosinophil fein granulirt, andere haben solche helle und dunkelblangrane Kerne zugleich, ihre Granula sind auch noch. hypeosinophil, doch etwas dunkler gefärbt; endlich bei anderen, mit nur graublauen Kernen, besteh t Granulirung theils gar nicht, theils nur in unbestimmbarer Weise. 
69. Glasige, graue Klümpchen, welche zahlreiche Staubzellen enthalten. In Methylenblau gefärbt, zeigen sich in Plasma ebensolche tiefblaue Körnchen, wie bei Fall 65. Thioninfärbung dagegen lässt nichts von Körnung bemerken.

Eisen-Pigmentzellen.

70. Mitral- und Aorten-Insufficienz. Das glasige, zähe Sputum enthält dunkelrothbraune Streifchen. In diesen finden sich massenhaft gruppirte, längsovale Zellen, meist. mit einem, seltener mit $z$ wei und mehr wandständigen Kernen, welche Eisenpigment theils in runden Klümpchen, theils in kerngrossen Schollen eingeschlossen haben. Einige Zellen sind geradeza als Riesenzellen anzusprechen. Das Plasma ist netzförmig durchbrochen, färbt sich in Eosin sehr blass. In demselben, sowie im Freien finden sich einige Myelintropfen. Ausser diesen sieht man theils unregelmässige, theils wurstförmige Gruppen leicbt ovaler, nahezu runder Zellen, etwa doppelt so gross, wie Leukocyten, welche theils feinkörnig pigmentirt, theils unpigmentirt, durchweg nur einen, meist centralen Kern besitzen. Viel gelbes und dunkelbraunes Pigment liegt frei. Die Rundzellen sind fein hypeosinophil granulirt, meist mehrkernig.

71. Hämorrhagischer Infarct bei ausgebreiteter Lungenphthise. Reichlich schleimig-eitriges Sputum mit dicken, hell- bis dunkelrothen Streifen. In diesen hauptsächlich rothe Blutkörperchen, viele Flimmer-Epithelien, einige grosse, polygonale PlattenEpithelien mit stark sich färbendem Plasma und centralem Kern, zahlreiche ein- und zweikernige Rundzellen und einige nicht pigmentirte, sehr grosse und vielkernige (Riesen-) Zellen von im Uebrigen gleichem Aussehen, wie die entsprechenden pigmentirten des vorigen Falles.

72. Mitralstenose. Acute Pericarditis. Ziemlich dünnflüssiges, grüngelbes, glasiges Sputum, in welchem eine kleine branrothe Faser eingebettet ist. Dieses enthält viele rothe Blutkörperchen; in geringer Anzahl, meist vereinzelt oder spärlich gruppirt, längsovale, abgerundete, feinkörniges Pigment führende Zellen von der Grösse etwa dreier Leukocyten bis zur Grösse grosser Plattenepithelien des Rachens, mit je einem wandständigen Kern. In Methylenblau zeigen sich innerhalb mehrerer dieser 
Zellen, besonders der grösseren, feinkörnige bis grobkörnige, in ihrer Grösse aber verschiedene und auch nicht ganz regelmässig runde, blane Körnchen. Mit Thionin lässt sich nichts von diesen Gebilden darstellen.

73. Aneurysma der Aorta.

Schleimig-eitriger Auswurf mit ziemlich frischen Blutstreifen und rostfarbenen Streifen. Neben zahlreichen Erythrocyten, Häufchen fein pigmentirter, meist zweikerniger ovaler Zellen, mit wandständigen Kernen, fanden sich in ersteren einzelne hypeosinophile Rundzellen. In letzterer ebensolche Pigmentzellen und ausser vielen grossen Platten-Epithelien zahlreiche hypeosinophile Rundzellen.

74. Mitral-Insufficienz und -Stenose.

Reichlicher schleimig-eitriger Auswurf mit zähglasigen, bräunlichen durchscheinenden Streifen. In letzteren finden sich zahlreiche gruppirte, jedoch nicht eng aneinander liegende ovale Zellen mit dunkelbraunem, grobkörnigem und scholligem EisenPigment, von doppelter bis etwa vierfacher Grösse der Leukocyten. Das Plasma derselben ist netzförmig durchbrochen, die Kerne (1-2, an den einkernigen manche von C-Form) meist wandständig. Die meist mehrkernigen Rundzellen sind fein granulirt, die Körnung färbt sich sehr. schwach hypeosinophil.

75. Mitralstenose.

Rostfarbenes, bis leicht orangerothes, klares, spärliches Sputum mit leichten Blutstreifen. Im klaren Theil sehr wenig Erythrocyten, massenhaft Rundzellen, meist mit einem, jedoch auch bis zu vier Kernen und intensiv hypeosinophil fein und gröber gekörntem Plasma, ferner zahlreiche pigmentirte Zellen. Das Pigment ist in diesen meist ganz diffus, sodass das Plasma gelb bis gelbbraun gefärbt erscheint, seltener differenziren sich einzelne gröbere Körner. Die Grösse vieler übertrifft kaum die der Rundzellen; viele andere sind doppelt und dreifach so gross. Die kleineren und viele der grossen sind einkernig mit engem Wandstand der Kerne, einzelne grössere haben zwei Kerne. Hie und da ist eine Zelle nicht diffus pigmentirt, sondern nur leicht gekörnt. Das Plasma dieser ist sehr blass (farbresistent); bei allen ist es netzförmig durchbrochen. Endlich sieht man eine Anzahl weder pigmentirter, noch granulirter plump-ovaler Zellen 
von etwa $1 \frac{1}{2}$ bis 2 facher Grösse der Rundzellen mit meist centralem grossem Kerne und sehr blassem Plasma.

76. Myodegeneratio cordis.

Spärlicher, dünner, glasig durchscheinender Auswurf mit leicht gelblichen Streifchen. Letztere enthalten viele, theils diffus gelbgefärbte, theils grössere Körner und Schollen gelben und braunen Pigments führende, rund-ovale Zellen mit blassem, netzartigem Plasma und wandständigem Kern. Die ziemlich zahlreichen Rundzellen sind mit mittelfeinen bis gröberen, schwach hypeosinophilen Granulis gekörnt.

Die Pigmentzellen des Sputum erscheinen hiernach nicht wesentlich verschieden untereinander, soweit ektogenes und endogenes Pigment in Betracht kommt, und gegenüber den pigmentirten Zellen der Bronchialdrüsen. Es würde za weit gehen, Identität anzunehmen, wohl darf aber auf den allen gemeinsamen Gegensatz gegen die bekannten Epithelien nachdräcklich verwiesen werden. Der kurzen Meinung v. Noorden's, dass „nichts für ihre Natur als Lymphocyten spreche“, können wir uns also nicht ohne Weiteres anschliessen.

Zunächst haben wir die Stellung des, bezw. der Kerne. Das einschichtige Plattenepithel trägt im Allgemeinen den Kern in der Mitte. Das Alveolar-Epithel speciell ist zum Theil grossplattig und kernlos. Wir sehen hier schon einen beträchtlichen Unterschied gegenüber den Pigmentzellen. Die Kerne, auch wenn mehrere vorhanden, stehen bei diesen so gut wie immer excentrisch, nahe der Wand, meistens direct an derselben (Fig. 7-9) Sie theilen dieses Verhalten mit den meisten der im Sputum sichtbaren Rundzellen. Weiter verhalten sich ibre Kerne tinctoriell anders, als die der, wenigstens im Sputum, deutlich als Epithelien erkennbaren Zellen. Der Kern der letzteren ist gewöhnlich stark gefärbt, häufig, besonders in Methylenblau, mit netzartiger Vertheilung des Chromatin. Die Kerne der Pigmentzellen färben sich gewöhnlich schlechter, bleiben blass und ziemlich gleichmässig gefärbt. Ebenso different ist das Plasma. In den Epithelien nimmt es Eosin sehr gerne, Methylenblau sehr wenig an, in den Pigmentzellen bleibt es gerade in Eosin recht blass, und nur in Methylenblan, wenn auch nicht stark, doch 
deutlich tingirt. Dabei zeigt es eine netzförmige Structur, theils durch netzförmige Vertheilung des Chromatinkörpers, theils durch Auftreten von Vacuolen bedingt.

Durchweg also ein tiefgreifender Unterschied zwischen dem im Sputum sicher als solches erkannten Epithel und den Pigmentzellen. Auch kommt noch ihre Grösse hier in Betracht. Diese schwankt von nicht mehr denn Leukocyten-Grösse bis zu 3-5 facher. Weist ersteres Verhalten (diese kleinsten Pigmentzellen waren auch stärker gefärbt) schon auf Rundzellen-Abstammung hin, so ist das Bild der ganz grossen und vielkernigen Zellen so ähnlich dem, was man im Gewebe als Riesenzellen bezeichnet, dass man wohl an Identität denken darf. Riesenzellen kommen nun nicht bloss in Geschwülsten, sondern, wie bekannt, besonders gern bei Tuberculose mit Einschluss von Bakterien, aber auch bei Reizen durch Fremdkörper vor. Wiederum eine Analogie, denn unsere Pigmentzellen als Fremdkörperzellen aufufassen, als Eliminatoren eingedrungener fremder Stoffe, liegt doch sehr nahe.

So bleibt denn so viel Gegensatz gegen Epithel, so viel Aehnlichkeit mit bekannten Zellen der Bindegewebs-Theile übrig, dass man wohl sagen darf: Bewiesen ist die bindegewebige Abstammung der Pigmentzellen des Sputums damit noch nicht, jedoch bilden alle jetzt bekannten Thatsachen kein Gegen-Argument gegen einen weiter zu führenden Beweis für diese $\mathrm{Ab}$ stammung, während jede Theorie der Entstehung dieser Zellen aus Epithel erst mit der Wegschaffung der vorangeführten Thatsachen beginnen müsste. Ja, wir dürfen sagen:

Würde nicht die Theorie vom Alveolar-Epithel bereits bestehen, so wïrde man, nach den heutigen Kenntnissen, nichterstan Aufstellung derselbendenken.

Vorliegende Arbeit wurde an der Klinik des Herrn Prof. J. Bauer ausgeführt. Für die gütige Erlaubniss hierzu und Gewährung des Materials erlaube ich mir hier meinen herzlichsten Dank abzustatten. Ebenso bin ich dem 1. Assistenten gepannter Klinik, Herrn Priv.-Doc. Dr. R. May, zu besonderem Danke für seine freundliche Unterstützung in Rath und That verpflichtet.

Herrn Ober-Med.-Rath Prof. Bollinger, sowie Herrn PrivatArcbir f, pathol. Anat. Bd. 158. Eeft 2. 
Docenten Dr. Barlow danke ich ebenfalls bestens für freundliche Ueberlassung einiger Untersuchungs-Objecte.

Literatur-Verzeichniss.

1. Panizza, Deutsches Archiv für klin. Medicin. 1881. 28. Bd. S. 343.

2. Schmidt, Zeitschr. f, klin. Medicin, 1892. S. 476.

3. Gollasch, Fortschritte der Medicin, 1889. 10. S. 361.

4. Leyden, Deutsche med. Wochenschrift, 1891. 38.

5. H. F. Müller, Centralblatt f. Allg. Pathol. und Pathol. Anatomie. 1894 V. Bd. S. $553 \mathrm{ff}$.

6. Fink, Inaug.-Dissert. Elberfeld 1890.

7. Lenhartz, Mikroskopie und Chemie am Krankenbett, S. 100.

8. Mandybur, Wiener Medic. Wochenschrift, 1892. 7-9.

9. Lenhartz, a. a. 0. S. 173.

10. Ehrlich, Die Anaemie. Wien 1898.

11. Kurlow, Wratsch, 1899. 23. 1892. 19.

12. Schmans und Albrecht, dieses Archiv, 1897. S. 1 .

13. H. F. Müller, Archiv für exper. Pathol. und Pharmakotherapie. S.-A. XXIX. Bd. S. 221.

14. Schaffer, Centralblatt f. d. med. Wiss. 1891. 22. 23.

15. v. Noorden, Zeitschr. f. klin. Med. 1892. 20.

16. Rieder, Beiträge zur Kenntniss der Leukocytose. Leipzig, 1892.

17. H. F. Müller, Centralbl. für Allg. Pathol. und Pathol. Anat. 1893 IV. Bd. S. 541,

18. S. Klein, Volkmann's Sammlung klin. Vorträge, Neue Folge. No. 87.

19. Ne u man n, Berl, klin. Wochenschr. 1898. 41.

20. Hankin, Centralbl. f. Bakteriol. 1892. Bd. 12.

21. Janowski, Archiv für exper. Pathol. u. Pharmako-Ther. 1895. Bd. 36.

22. Neusser, Wiener klin. Wochenschr. 1892. 3. 4.

23. Wirsing, cit. bei Cohn, In.-Diss., Würzburg 1890.

24. Zenker, Deutsches Archiv f. klin. Medicin, II. S. 116.

25. K n auff, dieses Archiv, 39. Bd. 3. S. 442.

26. Böhm und Davidoff, Lehrbuch der Histologie des Menschen. Wiesbaden 1898. 